Silvia Akemi Sato

\title{
Avaliação dos programas de uso racional de antimicrobianos em hospitais do estado de São \\ Paulo
}

Dissertação apresentada à Faculdade de Medicina da Universidade de São Paulo para obtenção do título de Mestre em Ciências

Programa de Doenças Infecciosas e Parasitárias - Mestrado Profissional

Orientadora: Profa. Dra. Anna Sara Shafferman Levin

São Paulo

2019 
Dados Internacionais de Catalogação na Publicação (CIP)

Preparada pela Biblioteca da

Faculdade de Medicina da Universidade de São Paulo

(C) reprodução autorizada pelo autor

\section{Sato, Silvia Akemi}

Avaliação dos programas de uso racional de antimicrobianos em hospitais do estado de São Paulo / Silvia Akemi Sato. -- São Paulo, 2019.

Dissertação (mestrado profissional)--Faculdade de Medicina da Universidade de São Paulo.

Programa de Doenças Infecciosas e Parasitárias - Mestrado Profissional.

Orientador: Anna Sara Shafferman Levin.

Descritores: 1.Infecção hospitalar 2.Gestão de antimicrobianos 3.Antiinfecciosos 4. Segurança do paciente 5.Farmacorresistência bacteriana múltipla 6.Qualidade da assistência à saúde

USP/FM/DBD-069/19

Responsável: Erinalva da Conceição Batista, CRB-8 6755 


\section{Agradecimentos}

À Profa. Dra. Anna Sara S. Levin e à Dra. Maura Salaroli de Oliveira pela orientação.

À Dra. Denise Brandão de Assis por ajudar na amostra deste trabalho.

Aos farmacêuticos que ajudaram a moldar meu perfil profissional.

Aos profissionais que atuam no controle de infecção, especialmente aos que contribuíram para a realização desta pesquisa. 
"Farmacêuticos, em todos os tempos e lugares, trazem mesmo lições de amor às pessoas. Aliás, para o farmacêutico, amar não é apenas o verbo transitivo direto que se aprende a conjugar, nas escolas. Amar é ação. A ação de servir, a qualquer hora de qualquer dia e em qualquer lugar. É cuidar, é promover a saúde, é salvar vidas”.

Carlos Drummond de Andrade 
Esta dissertação está de acordo com as seguintes normas, em vigor no momento desta publicação:

Referências: adaptado de International Committee of Medical Journals Editors (Vancouver).

Universidade de São Paulo. Faculdade de Medicina. Divisão de Biblioteca e Documentação. Guia de apresentação de dissertações, teses e monografias. Elaborado por Anneliese Carneiro da Cunha, Maria Julia de A. L. Freddi, Maria F. Crestana, Marinalva de Souza Aragão, Suely Campos Cardoso, Valéria Vilhena. 3a ed. São Paulo: Divisão de Biblioteca e Documentação; 2011.

Abreviaturas dos títulos dos periódicos de acordo com List of Journals Indexed in Index Medicus 


\section{SUMÁRIO}

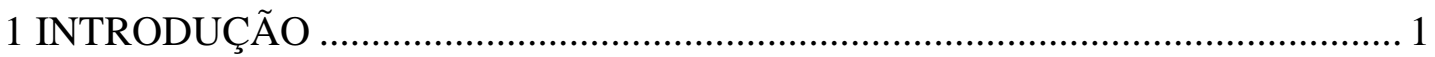

As bactérias multirresistentes ........................................................................... 4

Os programas de gerenciamento de antimicrobianos ............................................. 8

As estratégias dos programas de gerenciamento de antimicrobianos .................... 12

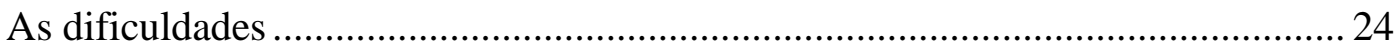

O impacto dos programas de gerenciamento de antimicrobianos ............................ 26

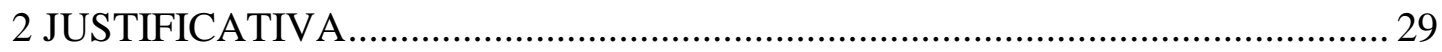

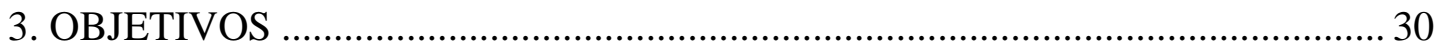

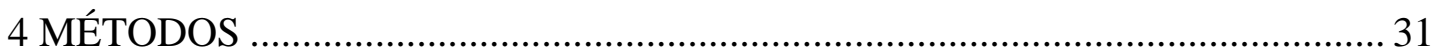

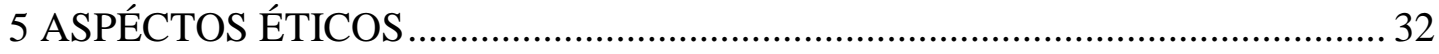

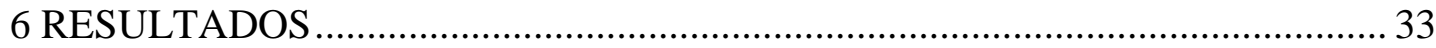

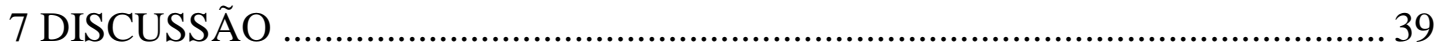

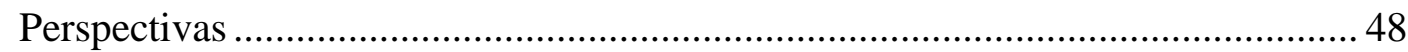

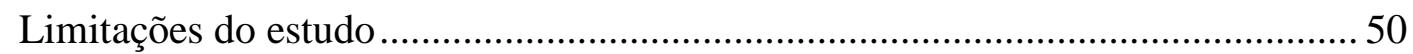

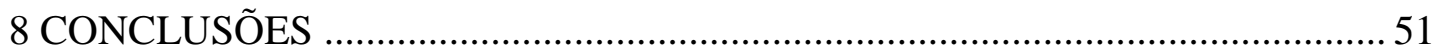

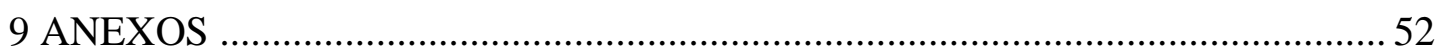

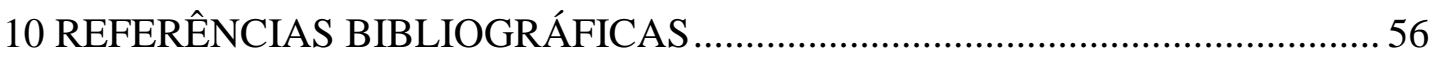

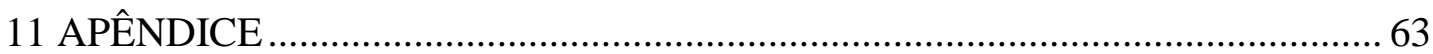




\section{Lista de siglas}

CCIH - comissão de controle de infecção hospitalar

PCIH - programa de controle de infecção hospitalar

CIM - concentração inibitória mínima

IRAS - infecções relacionadas à assistência à saúde

DNA - ácido desoxirrubonucléico 


\section{Lista de tabelas}

Tabela 1 - Lista de agentes patogênicos prioritários da OMS

Tabela 2 - Características referentes ao regime jurídico, capacidade de leitos e vínculo do corpo clínico dos 28 hospitais do estado de São Paulo em 2018.

Tabela 3 - Ferramentas ou estratégias dos programas de gerenciamento de antimicrobianos de 28 hospitais de São Paulo.

Tabela 3 (continuação) - Ferramentas ou estratégias dos programas de gerenciamento de antimicrobianos de 28 hospitais de São Paulo.

Tabela 4 - Indicadores utilizados pelos programas de gerenciamento de antimicrobianos em São Paulo no ano de 2018 36

Tabela 5 - Objetivos primários e secundários dos programas de gerenciamento de antimicrobianos 
Sato SA. Avaliação dos programas de uso racional de antimicrobianos em hospitais do estado de São Paulo [dissertação]. São Paulo: Faculdade de Medicina, Universidade de São Paulo; 2019.

As infecções relacionadas à assistência à saúde acrescentam custos monetários e humanos, principalmente quando são causados por bactérias resistentes aos antimicrobianos. A ocorrência de bactérias multirresistentes muitas vezes provoca a prescrição de antimicrobianos de amplo espectro o que leva a um círculo vicioso. Para evitar isso, os serviços de controle de antimicrobianos se esforçam em educar a equipe médica, criando as avaliações sistemáticas inseridas muitas vezes em programas de controle de antimicrobianos. Para realiza-las é necessário o planejamento e implantação de métodos, ferramentas e estratégias que incluem a préauditoria, a avaliação pós-prescrição, o uso de recursos laboratoriais e recursos humanos, tendo caráter restritivo ou educativo. Realizou-se uma pesquisa transversal com os hospitais de São Paulo, em que um questionário com conteúdo referente ao uso de antimicrobianos foi aplicado entre março e junho de 2018. Vinte e oito de 93 hospitais contatados aceitaram participar da pesquisa, dos quais 50\% eram hospitais públicos, $25 \%$ eram privados e outros $25 \%$ eram filantrópicos. A média de leitos total foi de 341, e 47 leitos de UTI. Em 93\% das instituições havia um programa de gerenciamento de antimicrobianos. Todos os serviços de controle de infecção contavam com médicos e enfermeiros, mas a proporção de serviços que contavam com farmacêuticos foi de $25 \%$. Apesar disso, $57 \%$ dos hospitais pesquisados tinham um farmacêutico atuando em algum momento do uso de antimicrobianos, o que constitui uma lacuna no uso responsável de antimicrobianos, já que este profissional é proficiente na orientação do uso correto de medicamentos. A estratégia mais comumente empregada foi a pós-auditoria com resposta ao prescritor. O protocolo de antibioticoprofilaxia esteve presente em $100 \%$ dos hospitais, mas apenas uma parte acompanhava a adesão ao protocolo, $11 \%$ utilizavam a pré-autorização para todos os antimicrobianos e $46 \%$ restringiam uma parte dos antimicrobianos. As visitas às unidades de internação foram relatadas por $93 \%$ das instituições e foi descrita como boa conduta por demonstrar parceria aos profissionais assistenciais. $67 \%$ possuíam uma diretriz para o uso e ajuste de vancomicina, 3\% o faziam para amicacina, $68 \%$ faziam infusão prolongada de betalactâmicos e carbapenêmicos. Verificou-se que $25 \%$ dos laboratórios de microbiologia não tinham disponibilidade de método automatizado de bactérias. A maior parte dos programas tem como principal estratégia, educar o prescritor. Os objetivos principais dos programas foram: a segurança do paciente e prevenção de ocorrência de bactérias multirresistentes. Os indicadores predominantemente utilizados para avaliar os resultados dos programas foram perfil de resistência das bactérias (77\%), infecção por bactérias multirresistentes (68\%) e consumo de antimicrobianos (64\%). Em conclusão, a maioria dos hospitais pratica alguma forma de avaliação dos antimicrobianos 
prescritos. Há lacunas quanto à atuação do farmacêutico no gerenciamento de antimicrobianos e nos recursos diagnósticos poderiam ser sugeridas melhorias.

Descritores: infecção hospitalar; gestão de antimicrobianos; anti-infecciosos; segurança do paciente; farmacorresistência bacteriana múltipla; qualidade da assistência à saúde 
Sato SA. Evaluation of antimicrobial stewardship programs in hospitals of the state of São Paulo [dissertation]. São Paulo: "Faculdade de Medicina, Universidade de São Paulo"; 2019.

Summary

Hospital-acquired infections adds economic and human costs, mainly the ones caused by drug resistant bacteria. The occurrence of multidrug resistant bacteria leads to prescription of broad-spectrum antibiotics, which can make a vicious circle. In order to avoid it, the infection control service make efforts to educate the medical staff by creation of systematic evaluation of prescription included um antimicrobial stewardship programs. To make it true, planning and implementation of methods and tools are needed including preauthorization, post prescription audit and feedback, lab and human resources. We have made a cross-sectional study with hospitals in São Paulo, a survey between march and June of 2018. Twenty-eight of 93 workers invited to participate o our survey accepted to answer the survey, $50 \%$ were public hospitals, $25 \%$ were private hospitals and $25 \%$ were philanthropic. The medium of beds were 341 , and 47 of ICU beds. In $93 \%$ of these hospitals there were antimicrobial stewardship program. All the infection control services there were a medical doctor and a nurse, but only $25 \%$ of them had in their staff a pharmacist. On the other hand, $57 \%$ of the participants had a pharmacist in some moment of the antimicrobial use. This was considered a gap, as they are a medicine specialist. The most frequently used strategy was the post-prescription with feedback. All the hospitals had their guideline for antibiotics for surgical prophylaxis, but part of them followed their use. Eleven percent used preauthorization for all the antimicrobial agents and $46 \%$ used a restriction list. The face-to-face in units were reported as good practice by $93 \%$ because it demonstrates partnership. Sixty-seven percent of them had guidelines for vancomycin use, $3 \%$ for amikacin and $68 \%$ uses prolonged infusion for beta-lactams and carbapenems. We identified $25 \%$ of the microbiology laboratory didn't had automated methods for bacteria identification. Most of the programs had as its mainly objective to educate the prescriber. The goals pointed by the participants were patient safety and prevention of multidrug bacteria. The predominant outcomes used to evaluate the programs were resistant bacteria profile (77\%), incidence of multidrug resistant bacteria infections (68\%) and antimicrobial consumption (64\%). In conclusion, most of hospitals has a way to evaluate the prescription of antimicrobial agents. There are some gaps in the pharmacist practice and in the diagnosis resources that could improve.

Descriptors: cross infection; antimicrobial stewardship; anti-infective agents; patient safety; drug resistance, multiple, bacterial; anti-infective agents 


\section{INTRODUÇÃO}

As infecções hospitalares.

A preocupação com as IRAS (Infecções Relacionadas à Assistência à Saúde) no Brasil teve seu marco com a primeira Comissão de Controle de Infecção Hospitalar (CCIH) criada em 1963 no Hospital Ernesto Dorneles. A legislação brasileira também fomenta a criação e funcionamento de serviços dedicados à função. A Lei Federal 9.431 de 6 de janeiro de 1997 obriga os hospitais a terem seus próprios Programas de Controle de Infecção Hospitalar (PCIH) (1).

Até início do século XX, as moléstias infecciosas não eram passíveis de cura. É conhecido o impacto que a epidemia da peste negra provocou na população europeia na era das grandes navegações. Além dela a tuberculose. Muito contribuiu para a queda de mortalidade a descoberta, por volta de 1940, de moléculas exibiam a capacidade de matar as bactérias, os antibióticos. Esse feito fez com que o mundo tivesse a visão de que toda a moléstia infecciosa pudesse ser sanada por antibióticos, impactando tanto nas vidas humanas quanto na vida das bactérias (2), (3).

A partir do advento da medicina e dos antibióticos, as doenças infecciosas deixaram de ser as doenças que mais acometiam a população, e enquanto a expectativa teve seu zênite quase alcançado, as doenças crônicas passaram a ser as de maior importância. As sociedades passaram a se preocupar mais com o câncer, a obesidade, a depressão, as doenças da senilidade. O Brasil vem seguindo a tendência mundial, fazendo a transição demográfica que significa queda na fecundidade e mortalidade ocorrendo simultaneamente com o aumento da expectativa de vida (4).

Apesar disso, as doenças infecciosas não podem ser negligenciadas. É agora preocupação mundial a resistência das bactérias aos antibióticos quando estas não sofrem a 
ação dos fármacos destinado ao tratamento de infecções. (5). É estimado que nos Estados Unidos, as bactérias resistentes causam 23 mil mortes ao ano além de custo adicional de 20 bilhões de dólares (3).

As quatro principais IRAS são as infecções de sítio cirúrgico, as infecções de corrente sanguínea, as pneumonias e as infecções do trato urinário.

No Brasil, as taxas de infecção de sítio cirúrgico podem variar largamente entre 1,4\% a $38,8 \%$, entre cirurgias gerais e específicas (6). Um estudo na Universidade de John Hopkins mostrou que o custo acrescentado por esse tipo de infecção pode ser de até US\$ $22.239(7)$.

É estimado que uma infecção de corrente sanguínea acrescente custos de US\$45,814, além de 10 dias de internação extra. Quando causado por Staphyloccocus aureus resistente a meticilina, o custo aumenta em $22 \%$ (8).

As pneumonias associadas à assistência à saúde representam a segunda mais frequente infecção nosocomial e é considerada a de maior mortalidade. Neste ambiente, os patógenos mais identificados, perfazendo $80 \%$ dos isolados, são o Staphylococcus aureus, seguido de Pseudomonas aeruginosa, Klebsiella spp., Escherichia coli, Acinetobacter spp., Enterobacter spp. O uso de antimicrobianos em 90 dias prévios está atrelado a maior ocorrência de bactérias multirresistentes, porém é fator protetor para ocorrência de bacteremias (9).

Mundialmente, as pneumonias são a causa da maioria das mortes em crianças, representando $15 \%$ das mortes dessas em idade abaixo de cinco anos em 2015. O patógeno mais comum é o pneumococo, apesar de sua ocorrência ter diminuído com a inserção da vacina e baixas taxas de tabagismo. Menos de 50\% das pneumonias têm diagnóstico microbiológico e um terço são causados por vírus, influenza (A e B), rinovírus, parainfluenza 1,2 e 3 e coronavírus (9). 
Os custos de pneumonia, segundo estudo holandês, podem variar de conforme idade e estado do paciente, numa amplitude de 344 euros para crianças até nove anos de idade com pneumonia adquirida em comunidade até mais de dez mil euros para pacientes em idade entre 50 e 64 anos de idade internados em UTI (9). 
As bactérias multirresistentes

Os processos pelos quais as bactérias desenvolvem resistência a antibióticos são complexos, envolvendo mutações de seu material genético ou aquisição de genes de resistência em estruturas genéticas móveis como os plasmídeos, os transposons e os integrons. (5).

Em muitas vezes está presente na bactéria mais de um mecanismo de resistência. Entre os fatores de risco associados à aquisição de bactérias multirresistentes estão o tempo de internação, a presença de procedimentos invasivos, o uso de antibióticos e internação em centro de terapia intensiva (10).

A resistência a antibióticos é um problema tão importante que em fevereiro de 2017, a OMS publicou a lista de patógenos que mais ameaçam a saúde humana. Trata-se de um ranking dividido em três níveis de prioridade com os nomes de 12 microrganismos resistentes aos antibióticos disponíveis no arsenal terapêutico mundial que são de maior importância por terem grande relevância clínica. O propósito desta lista é nortear a pesquisa e desenvolvimento de novos fármacos que sejam úteis no combate a essas infecções. Os patógenos podem ser vistos na tabela 1 (11). 
Tabela 1 - Lista de agentes patogênicos prioritários da OMS

Prioridade 1: CRÍTICA

Acinetobacter baumannii, resistente a carbapenema

Pseudomonas aeruginosa, resistente a carbapenema

Enterobacteriaceae, resistente a carbapenema, produtoras de ESBL

Prioridade 2: ALTA

Enterococcus faecium, resistente à vancomicina

Staphylococcus aureus, resistente à meticilina, com sensibilidade intermediária e resistência à vancomicina

Helicobacter pylori, resistente à claritromicina

Campylobacter spp., resistente às fluoroquinolonas

Salmonellae, resistentes às fluoroquinolonas

Neisseria gonorrhoeae, resistente a cefalosporina, resistente às fluoroquinolonas

Prioridade 3: MÉDIA

Streptococcus pneumoniae, sem sensibilidade à penicilina

Haemophilus influenzae, resistente à ampicilina

Shigella spp., resistente às fluoroquinolonas

Dentre as bactérias apontadas pela OMS, destacam-se as enterobactérias produtoras de betalactamase de espectro estendido, as ESBL, e resistentes a carbapenêmicos tidos como críticos. Sendo os betalactâmicos e os carbapenêmicos as últimas opções na terapia antimicrobiana, infecções por essas bactérias estão associadas a elevada mortalidade e portanto são de grande importância clínica (5).

Igualmente, a prevalência de bactérias que carregam os genes que expressam esses fenótipos de resistência tem aumentado (5). Na América Latina em 2014, por exemplo, a ocorrência de K. pneumoniae resistentes à terceira geração de cefalosporinas variou de $19 \%$ no Peru até $87 \%$ na Bolívia, enquanto no México, $41 \%$ das E. coli eram produtoras de ESBL. Também os genes de resistência se espalham muito rapidamente, o gene de metalo-betalactamase Nova Deli 1, que confere resistência a carbapenêmicos, foi primeiramente detectado num paciente sueco em 2008 e em 2013 já havia atingido 70 países (12).

No estrato classificado como prioridade alta, há os microorganismos resistentes à meticilina, à vancomicina, às quinolonas e à claritromicina. 
Os primeiros isolados de Enterococcus faecium resistentes à vancomicina (VRE) foram encontrados na Europa em 1987 e em 2013, 77\% das infecções nosocomiais por $E$. faecium eram resistentes à vancomicina (12). A vancomicina é droga de escolha para Staphylococcus spp. resistente à oxacilina (13).

Carregar VRE aumenta mortalidade, morbidade e custos hospitalares. O uso de vancomicina é fator de risco para aquisição de VRE para o indivíduo e impacta na colonização, matando as outras bactérias comensais de indivíduos que tenham VRE. No entanto, ainda são necessários estudos que provem que, isoladamente, a redução do uso de vancomicina possa ter impacto negativo sobre a ocorrência de VRE (14).

Na Europa, há evidência que a introdução de avoparcina, um glicopeptídeo, usado como fator de crescimento gado de corte, tenha laços com o surgimento de cepas resistentes à vancomicina. Enquanto nos Estados Unidos, o surgimento e espraiamento dessas bactérias resistentes tenham sido desencadeados pelo uso da própria vancomicina (15).

Em uma pesquisa feita no estado de São Paulo, a correlação entre consumo de antimicrobianos e ascensão de resistência a estes foi comprovada apenas para penicilina e a ocorrência de Staphylococcus aureus resistente à meticilina (MRSA). (16).

Há um estudo ecológico em 2015 correlacionando cinco anos de restrição de antibióticos com a redução da ocorrência de bactérias resistentes. Entre os anos de 2009 e 2013 houve redução significativa do consumo de antimicrobianos de 66,54 para 28,08 DDD/100, enquanto os índices de qualidade da assistência ou aumentaram ou permaneceram estáveis. A redução no consumo de antimicrobianos foi atrelada à redução ou estabilização de resistência de cinco bactérias mais importantes Escherichia coli, Acinetobacter baumannii, Staphylococcus aureus, Pseudomonas aeruginosa e Klebsiella pneumoniae (17).

Existem evidências de que concentrações plasmáticas de antibacterianos e antifúngicos abaixo das necessárias para eliminar patógenos sejam, além de ineficazes, 
favoráveis ao advento de resistência. Neste caso, têm sido de grande valor os estudos de farmacocinética-farmacodinâmica em pacientes especiais para auxiliar médicos em tomadas de decisão quanto à dose e regime posológico, otimizar a terapia, diminuir toxicidade e, num horizonte mais amplo, diminuir a possibilidade de surgir cepas resistentes (18).

O uso de antimicrobianos sem necessidade também traz consequências à população neonatal. Há publicações que mostram que o uso prolongado de antimicrobianos em neonatos pretermo está atrelado a risco aumentado de mortalidade, displasia broncopulmonar, enterocolite necrosante, retinopatias e danos da substância branca periventricular (19).

Finalmente, são vários os problemas decorrentes do uso indiscriminado de antibióticos que tem como agravante o aumento dos custos tanto com os antibióticos quanto com os custos indiretos relacionados aos eventos adversos ocasionados pelo seu mau uso ou à resistência aos antibióticos. A estratégia das indústrias farmacêuticas tem sido a de sintetizar novas moléculas de classes já existentes. Exemplo disso são as novas gerações de macrolídeos, quinolonas e betalactâmicos (20). Mas essa estratégia isolada não será suficiente, visto que é provável que algum mecanismo de resistência se expresse e se espalhe na população rapidamente. Torna-se imperativa uma política que vise a melhor escolha do antibiótico para cada situação otimizando a terapia. Talvez seja necessário associar várias medidas como testes diagnósticos rápidos, redes de vigilância e programas de gerenciamento de antimicrobianos. (3). 


\section{Os programas de gerenciamento de antimicrobianos}

Programas de gerenciamento de antimicrobianos são definidos de várias maneiras, incluindo conjunto de ações coerentes que promovem o uso responsável de antimicrobianos. Muitos programas de gerenciamento de antimicrobianos surgiram no departamento de farmácia incentivados pela necessidade de reduzir gastos com antimicrobianos pois estes representam grande fatia do orçamento (21). Porém o objetivo primário de um programa é o melhor cuidado com o paciente, prevenindo eventos adversos, melhorando os desfechos clínicos, individualmente, prevenindo a ocorrência de bactérias resistentes (22).

Muitas das publicações de uso racional de antimicrobianos, desde a década de 90, são encontradas como programas de stewardship de antimicrobianos, que é de difícil tradução.

Os primeiros trabalhos utilizando a palavra stewardship datam de 1996, quando os estadunidenses John E. McGowan Jr e Dale M. Gerding publicaram um texto interrogando: “A restrição de antimicrobianos previne resistência?”. Neste texto, eles problematizam a prescrição de antimicrobianos preocupados com a resistência bacteriana. Apontaram para a necessidade de se estudar os efeitos a longo prazo do uso de antimicrobianos para embasar as decisões clínicas (23).

O termo steward foi inspirado na expressão utilizada num sermão "being a good steward", para contribuir e apoiar a igreja (24). Após isso, o termo "antimicrobial stewardship" foi introduzido na IDSA e SHEA e passou a ser cada vez mais utilizado.

Não há uma definição universal para o que é o uso apropriado de antimicrobianos. Entre especialistas, é aceito que este seja o uso otimizado de antimicrobiano, a prescrição do antimicrobiano correto, na dose e intervalo entre doses apropriada às funções orgânicas do paciente, pelo tempo de terapia correta e via de administração melhor selecionada, de maneira a prevenir reações adversas às drogas e prevenir a ocorrência de bactérias multirresistentes (25). Dentre os objetivos de um programa de uso racional de antimicrobianos estão: a 
otimização de custos, a prevenção de efeitos adversos relacionados ao uso indiscriminado e a prevenção de bactérias resistentes (3).

As infecções por bactérias multirresistentes em ambiente hospitalar têm provocado mudança na frequência da prescrição de antibióticos de amplo espectro como terapia empírica, ou seja, antes da confirmação microbiológica do agente. Em 1999, o Conselho Federal de Medicina (CFM) publicou a Resolução 1552/99 a respeito da prescrição de antibióticos. Esta em seu primeiro artigo apresenta "prescrição de antibióticos nas unidades hospitalares obedecerá às normas emanadas da CCIH”. Ainda, obedecendo a princípios éticos, recomenda que as orientações emanadas da referida comissão devem ser baseada em evidência científica e que não deve ser subordinada a fatores econômicos (26)

O CFM reconhece que há médicos e conselhos regionais que consideram preservar a autonomia do prescritor, mas deve existir o dever ético de ambas as partes, tanto das CCIH de publicar recomendações plausíveis com os critérios científicos quanto do corpo clínico de ter o comprometimento com os pacientes e com a comunidade para diminuir a possibilidade de prescrições equivocadas e a ascensão da resistência bacteriana (26).

Entretanto, o processo do uso de antimicrobianos se estende além da prescrição. Para que seja realizado, o uso adequado de drogas antimicrobianas exige o esforço de toda a cadeia envolvida com o cuidado ao paciente, ou seja, é necessária uma abordagem multiprofissional. No tocante à assistência farmacêutica inserido num ambiente hospitalar, o uso de antimicrobianos envolve etapas que incluem a prescrição, a checagem da prescrição, a preparação e distribuição de medicamentos, a administração, o monitoramento e se necessário os cuidados pós-alta. Tais ações são desenvolvidas por uma equipe de médicos, farmacêuticos, técnicos de farmácia, enfermeiros, técnicos de enfermagem e microbiologistas (25). 
As estratégias dos programas de gerenciamento de antimicrobianos variam e podem ter abordagens, focos e objetivos diversos. Podem ter foco educativo ou restritivo, pode haver a restrição por meio de formulários, necessidade de autorização para prescrição de agentes antimicrobianos ou a prescrição pode ser livre com posterior auditoria e devolução aos prescritores. Além disso, o uso de ferramentas informatizadas também pode ser utilizada entre outras estratégias (3).

Na prática, uma metanálise de 2016 baseada em 26 estudos verifica a eficácia de um programa de uso racional de antimicrobianos em hospitais, em que as estratégias incluíram preaprovação, auditoria prospectiva, educação, implementação de protocolos, e formulários de restrição sendo que boa parte dos programas analisados utilizaram mais de uma estratégia. Em hospitais que implantaram mudanças na prescrição de antimicrobianos de alguma forma, seja restringindo ou por métodos passivos, houve redução no consumo de antimicrobianos restritos e alguns demonstram redução de forma generalizada, há redução também em dias de internação, ambos contribuindo para a redução de custos. Frisa-se que não foram detectadas diferenças na mortalidade e taxas de infecção entre os grupos controle e intervenção (27).

Recomendações da Infectious Diseases Society of America (IDSA) e da Society for Healthcare Epidemiology of America (SHEA) apontam que as intervenções de maior evidência com resultados mais significativos de um programa de uso racional de antimicrobianos são a pré-autorização e a auditoria prospectiva com devolutiva ao prescritor, cada uma com as suas vantagens e desvantagens, o que não exclui a instituição de outras medidas auxiliares (28).

As estratégias adotadas para o controle de antimicrobianos podem ser de natureza restritiva ou educativa. Não há consenso sobre qual é o método mais eficaz, a escolha do método dependerá das características do hospital, do corpo clínico, e do próprio serviço de controle de infecção (1). 
As medidas educativas são importantes no intuito de fornecer informações aos prescritores e orientar. Para essas ações a contribuição multiprofissional é imprescindível, integrando o laboratório na análise da epidemiologia do hospital, os farmacêuticos no fornecimento de informações sobre dados de farmacocinética, de interações medicamentosas, de incompatibilidade farmacotécnica, reconstituição e estabilidade de antimicrobianos (1).

A esse exemplo, num surto de Clostridium difficile, as primeiras providências foram o isolamento de pacientes com diarreia, reciclagem de pessoal, uso de hipoclorito de sódio depois de peróxido de hidrogênio na limpeza do ambiente, uso de termômetro individual a pacientes. Depois que todas essas medidas não resolverem o surto, a estratégia que funcionou foi a implementação de novas recomendações para antibioticoterapia. Essa consistia não em restringir mas em recomendar a substituição de cefalosporinas de segunda e terceira geração, ciprofloxacina, clindamicina e macrolídeos e também propor dias de tratamento para as doenças específicas. O resultado foi a redução do uso total de antimicrobianos e redução das infecções nosocomiais por Clostridium difficile (29).

Neste caso, o autor do estudo destaca que as medidas não restritivas, porém acompanhadas de motivação dos médicos, que neste caso eram os eventos adversos relacionados aos antimicrobianos, forma eficazes em alcançar o objetivo que era reduzir o consumo de antimicrobianos e aumentar a segurança do paciente (29).

O Centers for Disease Control and Prevention também publicou um documento que resume os elementos mais importantes de um programa de uso racional de antimicrobianos. Este documento propõe estratégias das mais diversas para serem adequadas a variedade de serviços (30). 
As estratégias dos programas de gerenciamento de antimicrobianos

A seguir são apresentadas algumas estratégias dos programas gerenciamento de antimicrobianos

\section{Pré-autorização e pós-auditoria com feedback}

Estas duas estratégias são elementos importantes para um programa de gerenciamento de antimicrobianos.

A pré-autorização é uma estratégia em que o prescritor deve solicitar a permissão antes de prescrever algum antimicrobiano eleito como restrito. Necessita de mais recursos humanos que a pós-auditoria, apresenta resultados mais consistentes na redução de uso inadequado de antimicrobianos, porém pode limitar a autonomia do prescritor e postergar a prescrição do agente antimicrobiano. Já a pós-auditoria permite a prescrição de antimicrobiano e posterior avaliação por especialista apto a autorizar ou modificar, mas seus efeitos na redução do uso de antimicrobianos pode levar mais tempo. Portanto, a terapia corre o risco de iniciar inadequadamente. Há vantagens se atrelado à educação do prescritor, já que ele deve receber um feedback após a correção da prescrição (28).

Em uma comparação entre os dois métodos, a pós-auditoria foi atrelado a maior consumo de antimicrobianos e a mais tempo de internação (31). A pós-auditoria com devolutiva ao prescritor tem a vantagem de ter um efeito de aprendizado e disso depende o sucesso desta estratégia, pois é também objetivo fazer com que o prescritor seja educado com os princípios da prescrição de antimicrobianos (28).

É desejável que suas recomendações dos executores de um programa de gerenciamento de antimicrobianos não sejam vistos como policiamento, mas que seus profissionais sejam reconhecidos como moderadores. Médicos e farmacêuticos dos programas de gerenciamento de antimicrobianos que fazem recomendações para modificar a 
droga prescrita ou seu regime posológico podem fazê-lo de forma persuasiva primeiro explicando o porquê dessas recomendações (32).

É importante a formação de uma relação de confiança com o corpo clínico nas conversas face-a-face em ganhar apoio. São mais agradáveis do que um texto de mensagem ou uma conversa rápida por telefone. Outro ponto é o trabalho em equipe multidisciplinar, fomentando interações multiprofissionais desde a formação, deixando claro que o cuidado com o paciente não é exclusividade dos médicos (32).

\section{Transição de terapia endovenosa para oral}

A transição via de administração endovenosa para via oral tem por objetivo fazer o intercâmbio dos antimicrobianos de forma que a dose disponível administrada por via oral alcance os mesmos níveis séricos da terapia endovenosa. Existem antimicrobianos que tem seus equivalentes em diferentes formas farmacêuticas e cuja biodisponibilidade é semelhante. Neste caso, há mais facilidade em haver a conversão. A dificuldade desta estratégia está nos fármacos que não são disponíveis em um modo de administração diferente (28).

A escolha da via de administração de antibióticos deve levar em consideração algumas características relativas ao objetivo da terapia e às condições do paciente. Para um paciente em situação crítica, é imperativo pensar numa maneira segura em que se atinja rapidamente o estado de equilíbrio dinâmico necessário para matar a célula bacteriana, assim a via intravenosa é muitas vezes escolhida por apresentar biodisponibilidade de $100 \%$ (33).

Dados europeus mostram uma frequência de antibióticos por via endovenosa de $70 \%$ em pacientes críticos, e às vezes permanecem internados por mais tempo somente para completar a terapia endovenosa, já que às vezes não há condições para executar o OPAT (Outpatient Parenteral Antibiotic Therapy). Para essa questão dentre as estratégias de utilizar melhor os antimicrobianos, os esforços para trocar precocemente a terapia endovenosa para a 
oral, medida que é benéfica do ponto de vista econômico, já que a terapia endovenosa utiliza especialidades farmacêuticas mais caras e também se ganha com o benefício de não necessitar manter o paciente com cateter, já que este dispositivo invasivo é fator de risco para ocorrência de infecções de corrente sanguínea e é gatilho para a desospitalização (33).

A depender da cultura disseminada na instituição, a troca de via de terapia ou o descalonamento pode ser de difícil aceitação, pois há o jargão "em time que ganha não se mexe". Ou seja, se com a terapia antimicrobiana, o paciente evolui bem há certa resistência em arriscar modificá-la (34).

\section{Otimização de terapia antimicrobiana}

As diferentes classes de antimicrobianos têm diferentes perfis farmacocinéticos, ou seja, a penetração nos tecidos, a absorção, a metabolização e a excreção. Desta forma, conhecer as interações do antimicrobiano com o corpo humano, bem como sua relação com o microrganismo que ele deve inativar, pode levar à melhor aproveitamento deste, otimizando a terapia ou minimizando seus efeitos indesejáveis (18)

A relação entre o fármaco e o corpo é a mensurada pela concentração plasmática através de coletas de amostras sanguíneas e espera-se que o nível sérico reflita a quantidade de fármaco no tecido afetado. Já a relação entre o antimicrobiano e o agente causador da doença é expressa matematicamente pela Concentração Inibitória Mínima (CIM). Assim, a correlação entre nível sérico e CIM é chamada modelagem pharmacokinetics/ pharmacodinamics $(\mathrm{pK} / \mathrm{pD})$ (18).

Esse monitoramento é especialmente importante em situações em que os parâmetros farmacocinéticos do paciente estejam alterados, em doentes críticos, com disfunção renal, obesos, queimados ou aqueles que tenham algum dispositivo invasivo, enfim, em todas as 
situações em que há modificação na cinética da droga e em quem possivelmente as doses padrão não atinjam seu objetivo terapêutico (35).

Segundo a IDSA, há na literatura forte evidência de que o monitoramento de aminoglicosídeos possa diminuir a incidência de nefrotoxicidade, o que não é tão evidente para vancomicina (28).

A classe de aminoglicosídeos foi primeiramente isolada na década de 40 e continua sendo muito utilizado tanto para o tratamento de infecções por gram-negativos quanto em associação com betalactâmicos. Apesar de serem de custo baixo, seu mau uso pode trazer prejuízos monetários significantes e aumentar a mortalidade e morbidade, pois um dos seus efeitos adversos é a nefrotoxicidade. Em um estudo para verificar o impacto do monitoramento dos aminoglicosídeos gentamicina e amicacina sobre a nefrotoxicidade, observou-se que o grupo com monitoramento farmacocinético apresentava menor chance de evoluir com aumento de creatinina que o grupo controle (5\% versus $21 \%$ ) apesar dos primeiros terem recebido doses maiores. Este aspecto é importante porque a eficácia de aminoglicosídeos é maior quanto maior for o pico plasmático (36).

Esta estratégia é possível com a implementação de protocolos de recomendação quanto aos horários para coleta de amostras, a conduta caso o nível sérico do antimicrobiano esteja fora da faixa esperada e recomendações para administração como tempo de administração e diluição correta (37).

\section{Implantação de sistemas informatizados}

Na busca por melhor qualidade da prestação de serviços, os hospitais têm implantado sistemas informatizados para contribuir para a redução de erros, de trabalho e de custos, como a prescrição eletrônica que utiliza o sistema de computadorizado de digitação da prescrição, o armazenamento e disponibilização de dados com maior agilidade, etc. (38). 
A adoção das tecnologias de informação possibilita a alimentação de bancos de dados que podem ser integrados e utilizados para criar um sistema de apoio à decisões (39). Desta forma, num hospital, esse tipo de ferramenta através da aplicação de conhecimentos específicos pode, dentre inúmeros dados e variáveis, fornecer ou ao menor indicar possibilidades de resposta (40).

Experiências demonstram que a implantação de sistemas de apoio à decisão deve ser feita levando em consideração todo o corpo clínico. Isso porque ela deve ser adaptada às necessidades de quem trabalha diretamente com o paciente (41). Se bem aplicadas, esta ferramenta pode auxiliar no gerenciamento de informações e aumentar a adesão aos protocolos de antibioticoterapia podem ser melhorados com a ajuda de sistemas de apoio à decisão e seus efeitos podem permanecer por longo período (42).

\section{Redução da duração de terapia}

Há a crença dentre médicos não-infectologistas de que duração de terapia muito curta possa contribuir para a resistência (34). A redução de dias de terapia é fortemente recomendada e pode ser parte dos objetivos de um programa de uso racional juntamente com as ordens automáticas de suspensão, à rotina da farmácia hospitalar ou atreladas à auditoria ou pré-autorização (28).

Há situações em que realmente há a necessidade de utilizar antimicrobianos por várias semanas como em situações de osteomielite e endocardite, porém caso seja viável o uso de antimicrobianos deve ser abreviado. Há publicações que demonstram que tratamentos mais curtos em comparação aos tratamentos mais longos são igualmente eficientes (43) (44).

Há estudos para pneumonia de comunidade que obtiveram sucesso em reduzir a curso de terapia de 10 a 7 dias sem diferenças em tempo de internação e readmissão em 30 dias (28). 


\section{Educação}

Uma das causas das prescrições de antimicrobianos serem inadequadas é a insuficiência de conhecimento dos prescritores. Os antibióticos não são prescritos apenas por especialistas como os outros medicamentos, por exemplo antineoplásicos, são prescritos por todas as especialidades e outros profissionais não-médicos como veterinários e odontólogos. Como agravo, existe dentre as especialidades médicas, o tribalismo, a baixa adesão ao trabalho em equipe, abordagens com conhecimento raso, etc. Daí deriva a necessidade de educar os prescritores desde a graduação e continuar atualizando-os através de campanhas educativas durante sua atuação profissional (34) (45).

Atualmente, há muito mais volume de informações e seu acesso é muito mais fácil que antes. Conhecimento errôneos a respeito dos antimicrobianos também são disseminados entre a pacientes e população em geral (34).

É demonstrado que moldar o comportamento é mais efetivo que tentar modifica-lo. Assim sendo, é recomendado que os cursos de graduação incluam em sua grade os princípios de disseminação de resistência. Um estudo entre estudantes demonstrou que menos de um terço desses tinham conhecimento acerca do espetro antimicrobiano (34).

Para melhorar a qualidade da prescrição de antimicrobianos podem ser feitas palestras, guias impressos, as aulas, a auditoria pós-prescrição com devolutiva ao prescritor. Apesar das dificuldades em inferir resultados, são mais efetivas as aulas em grupos pequenos e as diretrizes escritas. O IDSA classifica esta estratégia como complementar às outras estratégias, não sendo plenamente efetiva se aplicada sozinha (28). 
Infecções por Clostridium difficile

É uma forte recomendação que se faça restrição de antibióticos que ofereçam risco à aquisição de CDI como a clindamicina, as cefalosporinas de amplo espectro e as fluoroquinolonas (28).

O Clostridium difficile é uma bactéria gram positiva que forma esporos. Pode ser uma bactéria colonizadora do intestino humano sendo assim assintomática. Quando se instala uma infecção, pelo aumento do número em desequilíbrio da colonização noraml, essas bactérias passam a ser um grande problema sendo a causa da morte de aproximadamente 14 mil estadunidenses por ano (12). É a principal causa de diarreia intra-hospitalar podendo levar a casos mais graves como a colite pseudomenbranosa e colite fulminante. Seu manejo consiste em suspender os antibióticos sistêmicos, se possível, usar metronidazol como primeira escolha. Somente em caso de falha de metronidazol, utiliza-se vancomicina por via oral (46)

A infecção por Clostridium difficile foi primeiramente relatada em 1978. Na ocasião foi chamada de "colite por clindamicina" e a ação das toxinas A e B também foram descritas. É um evento associado ao cuidado à saúde que atinge preferencialmente as pessoas acima de 65 anos, e causa grandes prejuízos, aumentando a mortalidade, os custos e o tempo de internação além de causar impacto nas re-internações (47).

Os recursos de laboratório

\section{Identificação automatizada de bactérias}

A identificação do patógeno bem como os testes de sensibilidade direcionam a terapia antimicrobiana podendo encurtar o tempo de tratamento empírico. O método clássico de identificação dos agentes infecciosos envolve a cultura destes em meios que proporcionem os 
nutrientes e condições necessários ao seu crescimento e posteriores testes fenotípicos para identificar as diferenças metabólicas características de cada espécie (48).

Esse método manual de identificação de bactérias exige pouco custo com equipamentos, utilizando meios de cultura comerciais e equipamentos de baixo valor comparado com os métodos automatizados. Porém é mais trabalhoso e oferece risco de contaminação de amostras e risco de acidente de trabalho com perfurocortantes e biológicos durante o processamento e os sucessivos repiques.

Uma série de subcultivos são feitos a depender das primeiras características apresentadas na inspeção visual à procura de formação de gás, turbidez, películas, hemólise, coloração de Gram. A grande maioria dos agentes são isolados nas primeiras 72 horas (49).

Sistemas mais modernos de detecção, os métodos automatizados exigem um custo elevado, mas apresentam a vantagem de rapidez nos resultados, maior sensibilidade, registro em banco de dados e pouca necessidade de manipulação da amostra pelo trabalhador. A identificação dos resultados ocorre geralmente em até 48 horas. Exemplos de metodologias e equipamentos disponíveis no Brasil são: Bactec ${ }^{\circledR}$ modelos FX, série 9000 (9050, 9120, 9240), MGIT ® (para detecção de micobatérias) e BacT/ ALERT® 3D 60/120/240. Têm como princípio a detecção por fluorescência ou colorimetria (49). Os sistemas de monitoramento contínuo de hemocultura podem levar de um a um dia e meio para a detecção positiva (50).

A Bact/ ALERT (® (bioMérieux) consiste em detectar produção de dióxido de carbono dos tubos em que há amostras a cada 10 minutos, 24 horas por dia (51). O BACTEC $®$ (Baxter) monitora a cada 10 minutos a fluorescência emitida pela amostra e contém resinas inibidoras de antibióticos.

Acreditava-se que com a automação da identificação de bactérias, a detecção de patógenos necessitaria de menos amostras, pois seriam métodos mais sensíveis. Porém, 
Cockerill et al e Lee et al utilizando o sistema BACTEC ® sugerem que são necessárias quatro coletas de amostras num período de 24 horas para obtenção de $99 \%$ de sensibilidade. A coleta de apenas uma amostra tem sensibilidade em torno de $70 \%$, com duas amostras a sensibilidade aumenta para $80 \%$ a $90 \%$. Na terceira, aumenta para pouco mais de 95 a $98 \%$ (50), (52).

Alguns outros fatores podem dificultar a identificação de patógenos como, por exemplo, o uso de antimicrobianos no momento da coleta e o risco de contaminar a amostra. A detecção de fungos dimórficos pode levar até quatro semanas em cultura convencional, não sendo aconselhada automação na suspeita de infecção por fungos (49).

O uso de testes para identificação rápida é associado ao uso de antimicrobianos de menor espectro, porém seu uso deve estar associado à notificação rápida e suporte de um programa de gerenciamento de antimicrobianos para a rápida modificação de prescrição, a desvantagem dos métodos mais rápidos e automatizados é o custo de implementação (28).

\section{Testes para vírus}

Pandemias de gripe ocorrem ocasionalmente. $\mathrm{O}$ vírus da influenza foi primeiramente isolado em 1933. O método utilizado foi a inoculação de secreção de pessoas doentes em mucosa nasal de furões. Desde então se seguiram pesquisas sobre os tipos e subtipos, virologia e desenvolvimento de vacinas e tratamento (53).

A maioria dos agentes causadores de doenças respiratórias são vírus, mas é um desafio distingui-las das doenças causadas por bactérias pois os sintomas são inespecíficos. Dessa forma, a disponibilidade de testes virais rápidos, sensíveis e específicos poderia reduzir o uso desnecessário de antibióticos (53). 
Crianças são mais frequentemente atingidas por infecções por Streptococcus pneumoniae que adultos, mas boa parte das crianças que chegam ao pronto-socorro não apresenta infecção bacteriana (54).

Um estudo com pacientes pediátricos com sintomas de bronquite, infecção das vias aéreas superiores e resfriados, condições em que não há benefício em prescrever antibióticos em pronto-socorro verificou que médicos prescreviam antibióticos menos frequentemente a crianças de até quatro anos do que crianças em idade escolar. $\mathrm{O}$ autor atribui essa diferença à pressão feita pelos pais, pois em crianças que não permanecem em casa, os pais teriam mais conforto em saber que tudo o possível estaria sendo feito. Inferiu também que pediatras tendem a prescrever menos antibióticos que médicos de outras especialidades e atribui isso ao preparo diferente entre as especialidades. Mesmo assim, 44\% das crianças com resfriados, $46 \%$ com Infecções das vias aéreas superiores e $75 \%$ das bronquites resultam em prescrição de antibióticos (54).

No Brasil, chegou-se à conclusões similares, 59\% das população residentes de uma cidade sul-riograndense utilizou antimicrobianos para tratar infecções respiratórias, sendo a amoxicilina a mais frequentemente utilizada (55).

A importância de se diagnosticar corretamente influencia na qualidade do atendimento dispensado a crianças. Num estudo transversal, crianças abaixo de cinco anos tinham suas amostras testadas com Real-time Polimerase Chain Reaction PCR, menos que 5\% dos casos de pneumonia de comunidade eram de origem bacteriana. Mesmo assim, são mais frequentemente prescritos medicamentos para bactérias do que anti-virais (56) (57).

A detecção de vírus pode ser feita por cultura em células-ovo, com quase $100 \%$ de sensibilidade, mas esse método é muito moroso, sendo utilizado em desenvolvimento de vacinas e pesquisas quando não há a urgência para tratar o paciente (53). 
Por não terem mitocôndria ou metabolismo próprio, a sobrevivência dos vírus não é possível em culturas de ágar como as bactérias e fungos. O desenvolvimento de formas de detecção de antígenos ou anticorpos tornou possível o diagnóstico de doenças virais. A partir do desenvolvimento da biologia molecular, da descoberta de bactérias termófilas, do desenvolvimento da técnica de replicação de material genético, a reação polimerase em cadeia (PCR) tornou possível detectar DNA em mínimas quantidades (58).

O uso de PCR em tempo real é o princípio do teste de painel viral que identifica 17 tipos de vírus (59):

- Influenza A (sazonal, H3N2 e H1N1-2009), B e C

- Adenovírus

- Vírus respiratório sincicial A e B

- Rinovírus

- Coronavírus

- Parainfluenza 1, 2, 3 e 4

- Metapneumovírus

- Bocavírus

- Enterovírus

\section{Marcadores bioquímicos de inflamação}

Há sinais que o organismo apresenta que fornecem subsídio para se detectar uma infecção, os biomarcadores, como a proteína $\mathrm{C}$ reativa, a procalcitonina, a interleucina. $\mathrm{A}$ proteína-C-reativa é mais estudada sendo simples, rápida e custo-efetiva. Mas estará aumentada em qualquer situação de inflamação como dano em tecido, não sendo específica para uma infecção (19). 
Mais recentemente, a procalcitonina vem sendo pesquisada como biomarcador. Seu nível sérico sofre aumento em duas horas após a instalação de uma infecção, tempo inferior ao aumento de Proteína-C-reativa (19).

Há publicações que inferem que tanto o uso de proteína $\mathrm{C}$ reativa quanto de procalcitonina são úteis na tarefa de reduzir o uso de antibióticos desnecessário (60).

\section{Marcadores de infecções fúngicas}

As infecções invasivas fúngicas são de grande impacto na mortalidade e morbidade de pacientes, especialmente dos imunocomprometidos, isso inclui pacientes em curso de quimioterapia, transplantados, com HIV ou com deficiências primárias de sistema imunológico (61). O equilíbrio entre o exagero no tratamento empírico e no subtratamento pode estar em utilizar ferramentas diagnósticas auxiliares (62).

Em casos de suspeita de infecção fúngica, o uso de automação não é totalmente confiável, sendo preconizado o uso de cultura por lise-centrifugação e semeadura em ágar, mesmo assim, pode haver falha em 50\% dos testes em cultura (49).

Por esse tempo de espera de diagnóstico ser longo, meios de detecção foram desenvolvidos sem a dependência de crescimento de cultura, especialmente para Aspergillus spp., Candida spp. e outros fungos oportunistas incluindo a detecção de galactomana e betaD-glucana séricos ou em outras amostras como em lavado broncoalveolar. São de bom valor preditivo negativo, ou seja, são bons para excluir uma doença, em caso de teste negativo. Além desses, existem uso de PCR e detecção por antígeno (61).

Na ocorrência de Aspergilose pulmonar invasiva, o crescimento das hifas libera um açúcar de parede, a galactomana, que é detectável em sangue ou em lavado broncoalveolar. A detecção de galactomana é de importância para acompanhar o tratamento (61). 
A Beta-D-glucana é útil na detecção de doenças causadas por Aspergillus, Candida, Trichosporon, Fusarium, Exerohilum e de Pneumocystis jirovecii mas esse achado não pode distinguir entre as doenças fúngicas sozinho. É ainda de alto custo e mais frequentemente disponível em países desenvolvidos (61).

\section{As dificuldades}

Existem barreiras à implementação de um programa de gerenciamento de antimicrobianos. Os primeiros programas de gerenciamento de antimicrobianos foram produzidos e implementados em hospitais terciários com mais recursos onde o foco é a produção de conhecimento, o que não deve desencorajar hospitais de outras realidades. Uma revisão australiana com 18 estudos analisou publicações sobre o assunto e apontou como empecilhos a deficiência nos recursos humanos, a falta de profissionais com formação em doenças infecciosas, a falta até mesmo de recursos medicamentosos em hospitais rurais, entre outros. O mesmo estudo traz exemplos programas que conseguiram êxito com alternativas para suplantar os problemas relativos à implementação de programas de gerenciamento de antimicrobianos (63).

A ausência de especialistas em doenças infecciosas pode ser substituída por programas liderados por médicos e farmacêuticos que não são especialistas, programas externos ou até mesmo intervenção tecnológica (63).

Programas liderados por farmacêuticos hospitalares ou clínicos têm tido sucesso em reduzir o uso de antimicrobianos de amplo espectro e consequentemente de reduzir custos (64) (63).

Programas liderados por enfermeiros não foram relatados na metanálise de Bishop (2018), entretanto é fundamental a colaboração destes profissionais para o uso correto de antimicrobianos levando-se em conta que é o profissional mais próximo ao paciente (63). O processo de administração de antimicrobiano no tempo correto e com os cuidados na coleta 
de sangue para verificar nível sérico é fundamental para monitoramento terapêutico do antimicrobiano. A propósito, o monitoramento de nível sérico, a coleta de material para culturas, a infusão prolongada de betalactâmicos buscando a otimização de sua eficácia, a observação de reações adversas são algumas das habilidades destes profissionais (25).

Uma revisão que buscou identificar o estado atual dos esforços para implementação de programas mostrou que os pontos fracos da implementação de programas de gerenciamento de antimicrobianos residem na insuficiência de recursos humanos, além de orçamento, falta de padronização das medidas e a muitas vezes ficam restritos a um só setor da instituição, ou seja, a expansão para todos os setores do hospital também é um problema (65).

Os estudos de programas de gerenciamento são muito heterogêneos, tendo ferramentas, antimicrobianos, métodos muito heterogêneos e não são conclusivos a respeito do impacto sobre o padrão de sensibilidade das bactérias, além disso há nesses estudos outras intervenções que poderiam servir como fator confundidor como a própria instituição de práticas de controle de infecção (66). 
O impacto dos programas de gerenciamento de antimicrobianos

Os objetivos dos programas de gerenciamento de antimicrobianos podem ser diversos. Podem ser focados em reduzir custos, portanto medidos pelos gastos com antimicrobianos, ou podem ter como medidas os desfechos clínicos. Há evidências de que uso de terapia empírica de acordo com os guidelines instituídos, descalonamento, conversão de terapia intravenosa para via oral, monitoramento de terapia antimicrobiana, uso restrito de antibióticos e consultas com especialistas têm efeitos benéficos tanto sobre os desfechos clínicos, como diminuição de efeitos adversos, quanto de custos. (67).

Uma importante medida para destes estudos é a mortalidade, útil para demonstrar que as intervenções não são arriscadas aos pacientes. (67).

\section{Impactos clínicos}

Um dos impactos clínicos da redução da duração da terapia é a redução de eventos adversos associados ao uso prolongado de antimicrobianos. Por exemplo, o paciente está sob maior risco de desenvolver candidemia quando utiliza antimicrobianos de amplo espectro (68). Quando a colonização normal do intestino é comprometida com o uso de antibióticos de ação anaeróbia pelos antibióticos que chegam ativos às fezes, há prejuízo da colonização normal e então espécies comensais como Candida podem se multiplicar em excesso e invadir a circulação mesentérica (69).

Segundo um grupo de especialistas, um importante impacto causado pelo uso de antimicrobianos são as infecções por Clostridium difficile (70) ' É recomendação da IDSA que os programas de gerenciamento de antimicrobianos implementem estratégias para diminuir o uso de antimicrobianos associados à infecção de Clostridium difficile adquiridos em ambiente hospitalar (28). 
Reduzindo o tempo de uso de antimicrobianos, os programas de gerenciamento de antimicrobianos também fazem com que o tempo de permanência no hospital se reduza. Há demonstrações de que possa reduzir em até 9\% (27).

\section{Redução do consumo de antimicrobianos}

Num hospital italiano os custos com antimicrobianos representavam $26 \%$ do total de gastos com medicamentos com gastos anuais de mais de 3 milhões de euros. Neste cenário, foi adotado como método, o formulário de solicitação de antimicrobianos junto a mudanças nos protocolos e no guia de antimicrobianos da instituição e, na etapa de transição, muitas medidas educativas e feedback para os prescritores e esforço conjunto de médicos infectologistas do programa, farmacêuticos, farmacologista e administração. O resultado após a implementação do formulário foi a redução em nos gastos de mais de quase 350 mil euros ao ano, $10 \%$ de decréscimo em comparação com o ano anterior, devido à redução de $73 \%$ de consumo dos antimicrobianos restritos (71).

Uma pesquisa coreana que usou a restrição de antimicrobianos atingiu reduções significantes no consumo de carbapenêmicos, glicopeptídeos, oxazolidinonas e cefalosporinas de primeira, segunda e quarta geração. O método de restrição foi a principal intervenção, mas também houve a ajuda de um sistema computadorizado que verificava a prescrição redundante de antimicrobianos. Quando isso acontecia, o farmacêutico contatava o infectologista para verificar se a associação era adequada (72).

Uma metanálise com 26 estudos comparando pré e pós-intervenção chegou à conclusão de que a redução do consumo de antimicrobianos após a implementação de um programa de gerenciamento de antimicrobianos é de 19\%. Essa redução é ainda mais acentuada se contabilizada apenas a economia em UTI (39\%), nos antimicrobianos restritos (39\%), nos de amplo espectro (18\%), nos custos (34\%) (27). 
Impacto na resistência de bactérias

Há prováveis reduções na incidência de infecções por patógenos como Staphylococcus aureus resistente a gentamicina e a ciprofloxacina e Pseudomonas aeruginosa resistente a imipenem (72) (27).

Uma série temporal de cinco anos também chegou a redução de consumo de antimicrobianos atrelado a redução de $P$. aeruginosa resistente a imipenem, atribuído a redução do uso de carbapenêmicos e Klebsiella pneumoniae resistente a amicacina com a redução do uso de aminoglicosídeos (17). 


\section{JUSTIFICATIVA}

Tendo em vista a necessidade de promover o melhor uso de antimicrobianos, esta pesquisa busca obter informações acerca das ferramentas e estratégias, os recursos humanos e materiais disponíveis nos hospitais de São Paulo para detectar as dificuldades. 


\section{OBJETIVOS}

Verificar a aplicação das principais ferramentas e atividades para os programas de gerenciamento de antimicrobianos.

\section{Objetivos específicos}

- descrever as ferramentas e estratégias utilizadas;

- descrever o funcionamento e acompanhamento dos programas de gerenciamento de antimicrobianos;

- discutir as lacunas nas instituições participantes da pesquisa. 


\section{MÉTODOS}

Trata-se de um estudo transversal de natureza quali-quantitativa com coleta de dados primários através de entrevistas.

O instrumento utilizado para a coleta de dados foi um questionário elaborado pela pesquisadora, baseado nas recomendações do IDSA / SHEA e o CDC que norteiam a implantação de programas de gerenciamento de antimicrobianos (30) (28).

Os hospitais foram selecionados de acordo com pesquisa anterior que avaliou o impacto de medidas de intervenção em unidade de terapia intensiva do estado de São Paulo (73).

O primeiro contato, convidando os profissionais a participarem da pesquisa, foi feito através de telefone ou por meio de correio eletrônico. Os objetivos, a metodologia e a identificação dos pesquisadores eram explicados ao potencial participante.

Aplicação do questionário disponível em anexo (anexo 1) ocorreu por meio de entrevistas por contato telefônico e em formato de formulário enviado aos participantes e respondido eletronicamente. Foi feito um pré-teste com profissionais de nível superior, cujas respostas não forma adicionadas à amostra da pesquisa final.

\section{Local de pesquisa}

Este estudo foi realizado no estado de São Paulo, Brasil. 


\section{ASPÉCTOS ÉTICOS}

Os convidados a entrevista foram informados sobre os procedimentos e a finalidade da pesquisa. O projeto foi aprovado em comitê de ética sob o número 032597183.0000.0068 


\section{RESULTADOS}

No período de entre março de 2018 a julho de 2018 foram convidados 93 hospitais dos quais $28(30 \%)$ aceitaram participar.

Seis serviços justificaram a não participação. Dois serviços não participaram por não haver infectologista atuando no controle de antimicrobianos. Isso não os impediria de responder ao questionário, mas respeitamos a vontade do convidado. Três convidados não participaram por falta de autorização da administração do hospital, um serviço estava com o serviço de controle de antimicrobianos em implantação e preferiu não participar.

Em relação aos respondedores, $20(71 \%)$ eram médicos, $6(21 \%)$ enfermeiros e 2 (7\%) farmacêuticos. A média de tempo trabalhado no hospital atual variou de sete meses a 37 anos com média 12 anos. Oito entrevistados eram coordenadores do serviço de controle de infecção e três eram presidentes da CCIH.

As características dos hospitais participantes estão descritos na tabela 2. 
Tabela 2 - Características referentes ao regime jurídico, capacidade de leitos e vínculo do corpo clínico dos 28 hospitais do estado de São Paulo em 2018.

\begin{tabular}{|c|c|c|c|}
\hline Característica & Variáveis & $\begin{array}{l}\mathrm{N}=28 \text { dos que } \\
\text { aceitaram participar }\end{array}$ & $\begin{array}{l}\mathrm{N}=65 \text { dos que se } \\
\text { recusaram } \quad \mathrm{a} \\
\text { participar }\end{array}$ \\
\hline \multirow[t]{4}{*}{ Natureza jurídica } & & Número (porcentagem) & $\begin{array}{l}\text { Número } \\
\text { (porcentagem) }\end{array}$ \\
\hline & Público & $14(50 \%)$ & $27(41 \%)$ \\
\hline & Privada & $7(25 \%)$ & $22(34 \%)$ \\
\hline & Filantrópica & $7(25 \%)$ & $16(25 \%)$ \\
\hline \multirow[t]{3}{*}{ Número de leitos } & & Média (amplitude ) & \\
\hline & Leitos totais & $341(43-985)$ & - \\
\hline & Leitos de UTI & $47(7-188)$ & - \\
\hline \multirow[t]{3}{*}{$\begin{array}{l}\text { Vínculo do corpo } \\
\text { clínico }\end{array}$} & & Número (porcentagem) & \\
\hline & Fechado & $19(69)$ & - \\
\hline & Aberto & $7(31)$ & - \\
\hline \multirow{5}{*}{$\begin{array}{l}\text { Recursos humanos do } \\
\text { Serviço de controle de } \\
\text { infecção }\end{array}$} & & Média de profissional & \\
\hline & & /200 leitos & \\
\hline & Enfermeiros & 1,54 & - \\
\hline & Médico & 1,33 & - \\
\hline & Farmacêutico & $0,68 *$ & \\
\hline
\end{tabular}

* considerando apenas as instituições que têm farmacêuticos

Todos os entrevistados declararam haver no quadro de recursos humanos do serviço de controle de infecção ao menos um médico e um enfermeiro e 21 (75\%) serviços não tinham farmacêuticos. Oito serviços recebiam estagiários (29\%), seis serviços recebiam residentes $(21 \%)$. Três serviços tinham em seus quadros biomédicos e dois tinham técnicos de enfermagem.

Dos 28 hospitais, em 26 (93\%) havia programa de controle de antimicrobianos. Dos 26 serviços que disseram ter um programa de controle de antimicrobianos $22(85 \%)$ declararam ter um líder, dos quais 21 (81\%) são médicos.

Em todos os programas de gerenciamento de antimicrobianos, havia ao menos um médico que dedicava parte de seu tempo a esta função. Nove (32\%) contavam com enfermeiros e 16 com farmacêuticos (57\%).

As ferramentas e estratégias utilizadas pelos hospitais encontram-se descritos na tabela 3 . 
Tabela 3 - Ferramentas ou estratégias dos programas de gerenciamento de antimicrobianos de 28 hospitais de São Paulo.

\begin{tabular}{|c|c|}
\hline Ferramenta ou estratégia & $\mathrm{N}(\%)$ \\
\hline \multicolumn{2}{|l|}{ Ferramentas para apoiar a escolha de antimicrobianos } \\
\hline $\begin{array}{l}\text { Sistema de apoio à decisão para a prescrição de } \\
\text { antimicrobianos }\end{array}$ & $12(43)$ \\
\hline Disponibilidade de diretriz de antibioticoprofilaxia & $28(100)$ \\
\hline Disponibilidade de diretriz com condutas para sepse & $24(86)$ \\
\hline Disponibilidade de aulas & $21(75)$ \\
\hline \multicolumn{2}{|l|}{ Ferramentas de auditoria das prescrições de antimicrobianos } \\
\hline $\begin{array}{l}\text { Prática de visitas nas unidades de internação por membro do } \\
\text { programa de gerenciamento de antimicrobianos }\end{array}$ & $26(93)$ \\
\hline $\begin{array}{l}\text { Disponibilidade de consulta remota ao profissional do } \\
\text { programa de controle de antimicrobianos }\end{array}$ & $27(96)$ \\
\hline Avaliação sistemática de antimicrobianos & $24(86)$ \\
\hline Pré-autorização para todos os antimicrobianos & $3(11)$ \\
\hline Pré-autorização de lista restrita de antimicrobianos & $13(46)$ \\
\hline $\begin{array}{l}\text { Reavaliação da prescrição após o resultado dos testes } \\
\text { microbiológicos }\end{array}$ & $28(100)$ \\
\hline Auditoria pós-prescrição de antimicrobianos & $25(89)$ \\
\hline $\begin{array}{l}\text { Prática de resposta aos prescritores quanto às intervenções na } \\
\text { prescrição de antimicrobianos }\end{array}$ & $22(84)$ \\
\hline
\end{tabular}

Ferramentas para otimizar o uso de antimicrobianos

Mecanismos que reduzam o uso de terapia antimicrobiana 20 (71) redundante

Monitoramento de nível sérico de amicacina

Disponibilidade de diretriz para monitoramento de ajuste de 1 (3) amicacina

Monitoramento de nível sérico de vancomicina

Disponibilidade de diretriz para monitoramento e ajuste de 18 (67) vancomicina

Disponibilidade de diretrizes para ajuste de dose conforme 21 (75)

função renal

Disponibilidade de diretrizes para ajuste de dose conforme 11 (39)

função hepática

Prática de otimização de betalactâmicos / carbapenêmicos por 19 (68)

infusão estendida

Transição precoce de terapia endovenosa para oral

$13(46)$ 
Tabela 4 (continuação) - Ferramentas ou estratégias dos programas de gerenciamento de antimicrobianos de 28 hospitais de São Paulo.

\begin{tabular}{ll}
\hline Recursos laboratoriais & N (\%) \\
\hline Laboratório de microbiologia próprio & $20(71)$ \\
Identificação de bactérias através método automatizado & $21(75)$ \\
$\begin{array}{l}\text { Disponibilidade de teste viral rápido para patógenos } \\
\text { respiratórios (VSR, influenza) }\end{array}$ & \\
Disponibilidade de testes para toxinas de Clostridium difficile & $23(82)$ \\
Disponibilidade de teste para detecção de beta-D-glucana & $4(14)$ \\
Disponibilidade de teste para detecção de procalcitonina & $4(14)$ \\
Disponibilidade de teste para detecção de proteína-C-reativa & $26(93)$ \\
Disponibilidade de teste para detecção de galactomana & $12(43)$ \\
\hline
\end{tabular}

Foram citados três principais meios de consulta remota: o telefone institucional e aplicativo de smartphone.

A prescrição eletrônica está presente em 71 \% dos hospitais.

Tabela 5 - Indicadores utilizados pelos programas de gerenciamento de antimicrobianos em São Paulo no ano de 2018

\begin{tabular}{ll}
\hline Indicadores dos programas avaliados & $\mathrm{N}(\%)$ \\
\hline Perfil de resistência das bactérias & $22(77)$ \\
Incidência de infecção por bactérias multirresistentes & $19(68)$ \\
Consumo de antimicrobianos (DDD) & $18(64)$ \\
Adesão aos protocolos & $12(43)$ \\
Custos com antimicrobianos & $10(36)$ \\
Duração de tratamento & $8(29)$ \\
Taxa de infecção por Clostridium difficile & $4(14)$ \\
\hline Disponibilização dos indicadores & \\
\hline Somente lideranças do hospital & $17(61)$ \\
Liderança e corpo clínico & $11(39)$ \\
\hline
\end{tabular}

Objetivos do programa.

Sobre os objetivos primários e secundários do programa de gerenciamento de antimicrobianos, cada um os respondentes elegeram dois itens. A frequência das respostas está descrita na tabela 5 
Tabela 6 - Objetivos primários e secundários dos programas de gerenciamento de antimicrobianos

\begin{tabular}{ll}
\hline Objetivo & $\mathrm{N}=44(\%)$ \\
\hline $\begin{array}{l}\text { Diminuir a incidência de bactérias } \\
\text { multirresistentes }\end{array}$ & $22(50)$ \\
Aumentar a segurança do paciente & $18(41)$ \\
Reduzir custos & $4(9)$ \\
\hline
\end{tabular}

Sobre o que os entrevistados consideravam como ações efetivas para auxiliar no programa de controle de antimicrobianos, boa parte considerava que a presença nas unidades de internação era uma fundamental para a adesão às práticas do uso racional de antimicrobianos.

A participação de um profissional farmacêutico foi citada por cinco entrevistados como bom apoio aos programas de gerenciamento de antimicrobianos, seja na interface com a farmácia hospitalar, responsável pela dispensação de medicamentos, seja na execução de ações da farmácia clínica como o monitoramento de vancocinemia e controle da antibioticoprofilaxia.

Também foram citadas as vicissitudes no controle de antimicrobianos. A tradução das ações em indicadores, a falta de recursos humanos e falta de tecnologia da informação foram citadas como dificuldades.

O sistema informatizado foi citado como uma ferramenta catalizadora, pois facilita a visualização dos antimicrobianos prescritos, os dias de tratamento e a justificativa além de informar instantaneamente a prescrição de antimicrobianos.

Ainda em relação às dificuldades, um entrevistado demonstrou que as ações do programa de uso racional de antimicrobianos também deveriam ter interface com a administração para que a tomada de decisão de compras de antimicrobianos fosse adequada às tendências e às necessidades da epidemiologia do hospital. 
As diferenças entre o corpo clínico também foram lembradas, pois consideraram mais difícil executar o descalonamento com uma equipe de médicos que não são contratados pelo hospital.

Houve a descrição de uma tentativa que não obteve sucesso. Neste caso, o uso de fichas de controle de antimicrobianos não funcionou em seu serviço, referindo-se ao uso de documentos que são preenchidos pelo prescritor que mais tarde eram avaliados.

Foi mencionada a estratégia de rever a prescrição de antimicrobianos com os lembretes após certo tempo da prescrição da terapia como boa estratégia. 


\section{DISCUSSÃO}

$\mathrm{Na}$ última década, o número de trabalhos publicados com conteúdo sobre os programas de gerenciamento de antimicrobianos aumentou exponencialmente (24). Embora haja preocupação com o uso de antimicrobianos e com as bactérias multirresistentes, muitas vezes os médicos que assistem diariamente o paciente não têm auxílio para prescrever o antimicrobiano mais adequado (74). Para sanar problemas decorrentes do uso inadequado de antimicrobianos são utilizadas estratégias e ferramentas das quais algumas estão discutidas aqui.

Os recursos humanos dos programas de gerenciamento de antimicrobianos

A maioria dos hospitais que participaram desta pesquisa possuía um programa de uso racional de antimicrobianos. Nesta amostra, todos os serviços de controle estão de acordo com a resolução que norteia a prevenção de infecções hospitalares, a portaria 2616/98 (75), ou seja, mantém em seu quadro ao menos um enfermeiro e mais um profissional de nível superior de acordo com o porte do hospital. Em todos os hospitais que participaram, havia também ao menos um médico.

De acordo com o IDSA o núcleo de um programa de controle antimicrobiano deve ser constituído por um médico e um farmacêutico com especialização em doenças infecciosas (28). Apenas um quarto dos serviços de infecção contavam com um farmacêutico, embora a participação deste tenha sido citada como positiva para o controle de antimicrobianos.

No Brasil, a profissão farmacêutica, como muitas outras profissões, tem sofrido mudanças. A atuação do farmacêutico hospitalar era de aquisição, armazenamento e distribuição de medicamentos e atualmente estão sendo acrescentadas funções. $O$ farmacêutico está passando a ser inserido nas equipes multidisciplinares, no cuidado direto com o paciente, fazendo a reconciliação medicamentosa, a orientação de alta, o 
acompanhamento farmacoterapêutico, auxiliando na terapia medicamentosa e se necessário, acompanhando a compatibilidade das nutrições parenterais, verificando a existência de interações entre medicamento e nutriente, fazendo as intervenções junto à equipe multidisciplinar, visando melhor segurança na assistência à saúde (76).

São várias as referências aos profissionais farmacêuticos. Podemos citar Hepler e Strand como nortes para a atuação do farmacêutico a partir dos anos 1990, por motivar a mudança nas funções profissionais. Destaca que não basta dispensar o medicamento corretamente, pois é responsabilidade social do farmacêutico a prevenção de eventos adversos a drogas que matam mais de 12 mil mortes ao ano nos EUA, para isso, será necessário mudar o foco de produtos para pacientes (77).

Em alguns países já existem sociedades de farmacêuticos e especializações que treinam o farmacêutico a atuarem em doenças infecciosas. No entanto, em nosso meio, há carência de farmacêuticos clínicos com especialização em antimicrobianos e até mesmo o desconhecimento do seu papel tanto pelos administradores quanto pelo próprio corpo clínico (78) (79).

Em 2008, foi realizado o primeiro fórum nacional de educação farmacêutica em Brasília. A discussão central foi entorno do tema "o farmacêutico que o Brasil precisa". Uma das conclusões a que se chegou foi de que a formação dos farmacêuticos não corresponde às reais necessidades sociais, sendo pouco comprometida a resolver os problemas de saúde no Brasil. Foi destacado que o foco dos cursos de graduação são produção de medicamentos, técnicas e exames, mas pouco centradas no paciente (80).

Neste referido fórum, ficou evidente a necessidade de mais cursos de pós-graduação e o fomento às pesquisas relacionadas à atenção farmacêutica. Da mesma forma, pode ser necessária a criação de formas de educação que preparem o farmacêutico para atuar também no controle de antimicrobiano. 
Outro possível ponto a ser considerado é a que a limitação profissional do farmacêutico se deve também aos papéis nas relações interprofissionais e organizacionais da cultura da instituição.

\section{Ferramentas para apoiar a escolha do antimicrobiano}

Para auxiliar a tomada de decisão quanto à prescrição de antimicrobianos, podem ser disponibilizadas diretrizes, protocolos, sistemas informatizados que filtrem informações relevantes, entre outras ferramentas que corretamente guiem a adequação da prescrição (81).

No presente estudo, foram verificadas a disponibilidade de diretrizes para antibioticoprofilaxia cirúrgica, diretrizes para sepse, disponibilidade de aulas sobre doenças infecciosas e sistemas de apoio à decisão.

A respeito das diretrizes, os que tratam de antibioticoprofilaxia cirúrgica estão presentes em todos os hospitais entrevistados. Esta medida pode fazer parte prevenção de infecções de sítio cirúrgico, mas deve ser acompanhada de outras medidas para prevenir este tipo de infecção. A última versão do Centers for Disease Control and Prevention Guideline for the Prevention of Surgical Site Infection publicado em agosto de 2017 aborda essa questão. A utilização de antimicrobianos profiláticos é recomendada caso haja evidência de sua eficácia no tipo de cirurgia e também se deve levar em consideração os estudos farmacocinéticos para determinar o tempo de administração ideal para que a concentração no tecido que sofra a incisão seja a adequada (82), (83).

Oitenta e seis por cento dos hospitais da amostra tinham diretrizes para sepse também. O acesso aos protocolos pode ser diferencial na sobrevida e tratamento correto do paciente, já que a mortalidade por sepse é de mais de $25 \%$ (84).

Verificou-se que pouco mais de $40 \%$ dos hospitais afirmam ter sistema de suporte à decisão. Não foi possível aferir o quanto esta ferramenta é utilizada pelos prescritores. Este 
dado contrasta com uma pesquisa canadense que chegou à proporção de $12 \%$ as instituições que utilizam o sistema de apoio à decisão (85).

Apesar dessa proporção de hospitais que têm sistemas de apoio à decisão, há uma parte dos entrevistados que declararam não haver prescrição eletrônica, que seria um passo anterior à implantação de sistemas de apoio à decisão. Quase 30\% de nossa amostra não têm prescrição eletrônica.

A prescrição informatizada é um sistema que permite que o médico redija diretamente no computador, evitando erros por caligrafia e as informações incompletas. Pode-se desenvolver softwares internamente, contratar terceiros ou comprar "pacotes" ou soluções prontas. A adoção desses sistemas facilita também a implantação de sistema de dose unitária e racionalização do uso de medicamentos (86).

A falta de prescrição eletrônica pode comprometer avanços não só na melhoria da prescrição de antimicrobianos, mas também na qualidade da prescrição em geral, levando em consideração que a utilização da informática em serviços de saúde melhora a coleta e armazenamento de dados e previne erros, provendo uma prescrição legível e mais completa que a prescrição manuscrita (87).

Além dessas ferramentas, o investimento em educação do prescritor também é considerada. Os esforços para educar equipe estão presentes na maior parte dos hospitais. Prescrever antimicrobianos não é exclusividade do infectologista, portanto, educação para os prescritores começa no ensino superior onde conceitos serão apresentados e deve continuar transversalmente atualizando-os durante a vida profissional no intuito de moldar as práticas cotidianas (45).

É elementar a inclusão de tópicos que tragam a graduandos os problemas e soluções do uso de antimicrobianos. Uma pesquisa feita com futuros farmacêuticos estadunidenses concluiu que quase a totalidade dos entrevistados consideram os conhecimentos sobre 
antimicrobianos importante, $80 \%$ gostariam de mais informações sobre resistência e uso correto de antimicrobianos, mas pouco mais da metade se consideravam preparados a fazer intervenções nas prescrições de antimicrobianos (88).

\section{Ferramentas de auditoria das prescrições de antimicrobianos}

Em mais de $90 \%$ das instituições, algum membro do programa de gerenciamento de antimicrobianos realizava visitas às unidades de internação. Isso foi também relatado na pesquisa qualitativa, pois existe a percepção de que a presença nas unidades de internação possa fazer a diferença na efetividade dos programas.

A inserção de um profissional do programa de uso racional de antimicrobianos na equipe multidisciplinar não só tem a finalidade de educar os profissionais que prestam assistência direta, mas também prepara o profissional auditor para as particularidades de certo paciente. Exemplo disso é a atuação do profissional do programa de controle de antimicrobianos em um setor de oncologia ou transplante onde serão adquiridos conhecimentos da evolução da doença ou sobre a imunossupressão. Dessa troca de informações e convívio diário é natural que se estabeleça parceria, confiança e o tomada de decisão compartilhada a respeito da prescrição de antimicrobianos (89).

No tocante aos métodos de intervenção, dois dos elementos principais de um programa de gerenciamento de antimicrobianos são a pré-autorização e a auditoria pósprescrição com feedback, mas podem ser utilizadas outras estratégias complementares como a educação, a otimização, o descalonamento e a troca de antimicrobiano endovenoso para oral (90).

Nesta amostra, poucos serviços utilizam a pré-autorização para todos os antimicrobianos enquanto quase metade utiliza para uma lista restrita de antimicrobianos e o restante não restringe nenhum antimicrobiano antes da prescrição. Quase 90\% dos serviços 
fazem a auditoria pós-prescrição, com isso pode-se deduzir que a maioria dos hospitais utiliza um sistema misto de avaliação das prescrições de antimicrobianos.

São relatadas experiências de pré-autorização desde 1974 por Mc Gowan e Finland já apresentando resultados em reduzir o uso de antibióticos restritos e consequentemente seus custos (91). Por outro lado, esta forma de controlar a prescrição de antimicrobianos pode restringir a ação dos prescritores e por isso adquirir impopularidade por parte destes (92). Novamente destaca-se aqui o trabalho em equipe para formação de parcerias e evitar a visão policial dos programas de antimicrobianos. Além disso, exige que haja ao menos um auditor para avaliar as prescrições diuturnamente, por esse motivo, acreditamos que esta não seja a estratégia principal dos hospitais entrevistados.

Todos os programas de controle de antimicrobianos avaliados neste estudo praticam a revisão da prescrição após a obtenção dos resultados microbiológicos. Essa prática é essencial para realizar as atividades de descalonamento, reduzindo o uso de antimicrobianos de amplo espectro, e para a troca de via de administração de endovenoso para via oral. Todavia, somente $46 \%$ dos entrevistados disseram ter essa última atividade sistematizada.

\section{Ferramentas para otimizar o uso de antimicrobianos}

Sabendo-se que a pesquisa e desenvolvimento de antimicrobianos têm seus limites de tempo e investimento, faz-se necessário que o uso do arsenal terapêutico existente seja feito da melhor forma possível, ajustando a dose e posologia conforme as funções orgânicas do paciente e a natureza do fármaco, reduzindo o uso de medicamentos por via parenteral e evitando o uso de antimicrobianos de mesmo espectro.

As diretrizes conforme função renal estão presentes em $75 \%$ das instituições enquanto guias para prescrição de antimicrobianos em caso de função hepática estão em 39\% das 
instituições. Diretrizes como estas podem auxiliar muito o prescritor quanto a tomada de decisão em caso de disfunção orgânica.

Era esperada maior frequência de hospitais que tivessem diretrizes sobre o ajuste de dose por função renal e menor frequência dos que tivessem conforme hepática, pois o primeiro é mais acessível que o segundo.

Pouco mais de um quarto dos hospitais têm a disponibilidade de testes laboratoriais do nível sérico de amicacina e apenas um destes tem um protocolo para monitoramento e ajuste deste antimicrobiano, posto que esta ação reduz a incidência de nefrotoxicidade e, portanto, seja uma medida que beneficiaria pacientes em risco de desenvolver disfunção renal.

O teste para verificar nível sérico de vancomicina está presente em $61 \%$ hospitais dos quais todos têm protocolo de ajuste e monitoramento de vancocinemia, um hospital declarou ter um protocolo, mas não haver disponibilidade do teste no momento da pesquisa. Desta forma o monitoramento de vancomicina foi mais prevalente que o de amicacina.

Em teoria a infusão prolongada de betalactâmicos tem vantagem farmacocinética sobre a infusão intermitente, convém lembrar que devemos considerar as dificuldades em manter um acesso exclusivo para a infusão destes e a necessidade de educação da equipe assistencial (93). Não obstante, o número de hospitais que conseguem executar a infusão contínua de betalactâmicos é de $68 \%$.

\section{Os recursos laboratoriais dos hospitais avaliados}

Para o uso correto de antimicrobianos é importante saber qual agente infeccioso é o causador da infecção. Para isso são utilizados métodos de identificação direta do agente e sua sensibilidade. Contudo, outros testes podem ser realizados a fim de auxiliar o diagnóstico e tratamento de doenças infecciosas, tais como testes de marcadores bioquímicos de 
inflamação, que detectam moléculas produzidas em resposta à invasão de um agente infeccioso e os testes com marcadores de infecção fúngica, normalmente moléculas que constituem a estrutura orgânica dos fungos.

Vinte e cinco por cento das instituições utilizam cultura para a identificação de bactérias ao invés de métodos automatizados de identificação. $\mathrm{O}$ alto investimento inicial pode ser um fator que limite a obtenção de equipamentos para a identificação por método automatizado. Mas este investimento pode ser justificado pela maior biossegurança e menor tempo de detecção comparada à do método manual.

Do mesmo modo, é demonstrado na literatura que a utilização de métodos rápidos de detecção e identificação de patógenos têm potencial em encurtar o tempo de terapia empírica fazendo com que o descalonamento seja realizado com menor tempo se comparado aos métodos que utilizam cultura de bactérias (94). Além do impacto sobre o tempo de terapia, os métodos que utilizem a automação ou até a biologia molecular, juntamente a uma equipe de gerenciamento de antimicrobianos, podem diminuir os custos e até mesmo trazer benefícios clínicos, diminuindo a mortalidade atrelada ao tratamento inadequado (95).

Outra medida que poderia reduzir o uso desnecessário de antimicrobianos é o uso de biomarcadores de inflamação e seus algoritmos. O uso de proteína-C-reativa foi mais comumente citado que procalcitonina em nossa amostra.

Por se tratar de uma proteína não específica para infecção, uma metanálise conclui que utilização de proteína-C-reativa deve ser acompanhada de exames clínicos, o que não exclui seu valor como preditor de infecções (96). Em ensaio randomizado comparando ambos, não houve significativa diferença na redução de terapia antimicrobiana, mas a procalcitonina foi superior em reduzir os dias de terapia antimicrobiana e é demonstrado também em alguns estudos seu potencial em reduzir mortalidade (97) (98). 
No que concerne aos marcadores de infecção fúngica, pouco mais de $40 \%$ das instituições participantes utilizam galactomana e 14\% utilizam beta-D-glucana. São indicados em situações restritas como em doenças hematológicas, ou seja, em pacientes em alto risco de adquirir doenças fúngicas invasivas podendo indicar o início da terapia preemptiva, acreditase que por isso não foram relatados em parte considerável da amostra.

\section{Os indicadores dos programas de uso racional de antimicrobianos}

A tradução do resultado em números foi citada como uma das dificuldades de se trabalhar com o controle de antimicrobianos. O acompanhamento das ações é fundamental ao seguimento das intervenções em saúde através de dados com o intuito de informar o quanto as ações estão sendo efetivas para alcançar os objetivos e também para a realização do Benchmarking (99).

Os indicadores de um programa de gerenciamento de antimicrobianos podem aferir os custos, os resultados microbiológicos, o impacto para os pacientes (100). Nesta pesquisa, os indicadores mais comumente utilizados encontrados foram o perfil das bactérias resistentes, incidência de infecções por bactérias multirresistentes e o consumo de antimicrobianos. Não se encontrou nenhum indicador dos programas que fosse comum a todos os hospitais, o que poderia dificultar a comparação entre eles. Um inquérito realizado em Ontario também não conseguiu encontrar nenhum indicador em comum dentre todos os hospitais daquela pesquisa (85).

Nos sistemas públicos de saúde os gastos com o setor farmacêutico são crescentes e mesmo assim não resultam em melhora dos indicadores. Em alguns países este pode comprometer $37 \%$ do orçamento destinado à saúde (101). É fundamental para o uso racional de medicamentos que se façam estudos farmacoeconômicos, incluindo os medicamentos antimicrobianos (102). 
Neste estudo, a redução de custos não foi prioridade para a maioria dos hospitais, sendo preterido em razão dos objetivos serem preferencialmente a segurança do paciente e a prevenção de bactérias multirresistentes. Pouco mais de um terço desses utilizam como indicador os custos relacionados ao uso de antimicrobianos apesar de programas de gerenciamento comumente demonstrarem redução do consumo e custos.

Por outro lado, observar somente os custos no anseio que estes reduzam pode ser frustrante. Num estudo em Porto Alegre, o aumento de adesão ao protocolo de neutropenia febril da instituição foi associada a maior consumo de anti-infecciosos como a vancomicina e o metronidazol mas também foi associado a menor mortalidade (103). Além disso, a redução de custos, provavelmente, será sustentada por um tempo até que atinja um consumo mínimo.

Embora na maioria dos hospitais exista disponibilidade de testes toxinas de Clostridium difficile (82\%), a taxa de CDI é transformada em indicador em apenas $14 \%$ das instituições. Da mesma forma, tendo todas as instituições alguma diretriz para uso de antimicrobianos no período perioperatório, poucos monitoram a adesão ao protocolo.

Sobre a divulgação dos resultados, boa parte afirmou disponibilizar os resultados a todos. É de bom grado que a divulgação dos resultados à equipe assistencial seja acompanhada de uma discussão sobre as causas e as consequências e para decidir, de forma compartilhada, qual será o plano de ação a partir da visualização dos dados.

\section{Perspectivas}

Para Koselleck, um historiador alemão, “os homens são responsáveis pelas próprias histórias em que estão envolvidos". Há em sua obra Futuro passado a teoria de que os homens constroem suas aspirações de acordo com aquilo que conhecem da história da humanidade. Existe daí a relação entre o passado e o futuro, ou o que ele denomina o espaço experiência e o horizonte de expectativa (104). 
$\mathrm{Na}$ experiência passada vivida ou a experiência alheia é que se moldam os pensamentos racionais quanto os comportamentos e tomadas de decisão. Já a expectativa reúne as esperanças, medos e também o planejamento racional (104).

O uso da expressão horizonte de expectativas não é utilizado à esmo. É o horizonte uma linha por trás da qual se abre o futuro. Nas enciclopédias "horizonte é um linha imaginária que separa a terra do céu, e que se torna mais distante quando dela nos aproximamos".

Da mesma forma aquilo que se almeja como ideal para a assistência à saúde é parcialmente aquilo que já foi vivido ou relatado na literatura. Apesar das limitações deste estudo, o horizonte de expectativas que esta pesquisa ousou apresentar pode ser resumido nas seguintes ações:

- Desenvolvimento de software para o controle de antimicrobianos que alertem prescrição duplicada de antimicrobianos do mesmo espectro que informe alergia e lembrem o prescritor de revisar a prescrição de antimicrobianos sempre que necessário;

- Investimento nos laboratórios de microbiologia no que diz respeito às formas de identificação de bactérias e testes rápidos para vírus respiratórios;

- Campanhas de conscientização dos profissionais de saúde e da população sobre a resistência bacteriana;

- Incentivo à inclusão de metas para troca de medicamentos endovenosos para via oral;

- Maior envolvimento de profissionais em estudos e difusão da necessidade de ajuste de dose conforme função hepática;

- Planejamento de educação continuada para preparo e inserção do farmacêutico no uso responsável de antimicrobianos, tanto daqueles que atuam em drogarias, quanto os farmacêuticos clínicos. 


\section{Limitações do estudo}

Este estudo se propõe a delinear um perfil dos programas de controle de uso racional de antimicrobianos atuantes nos hospitais do estado de São Paulo. Porém existe a possibilidade de haver viés de não participação já que a adesão foi de 28 de 93 hospitais. Outra limitação do estudo é a falta de validação das respostas, pois em nenhum momento foram solicitadas demonstração das ferramentas. 


\section{CONCLUSÕES}

- A maioria dos hospitais de São Paulo pratica algum mecanismo de controle de antimicrobianos;

- As principais estratégias utilizadas são a auditoria pós-prescrição com feedback, o uso de diretriz para antibioticoprofilaxia e sepse;

- Não há um indicador utilizado para aferir os programas de gerenciamento de antimicrobianos que seja comum a todos os hospitais;

- As principais metas dos programas de gerenciamento são relacionadas à segurança do paciente e à prevenção de bactérias resistentes;

- Há uma lacuna na atuação do farmacêutico no uso racional de antimicrobianos. 


\section{ANEXOS}

Anexo 1 - Questionário aplicado aos hospitais participantes da pesquisa "Avaliação dos programas de uso racional de antimicrobianos em hospitais do estado de São Paulo"

Nome do hospital

Seu cargo:

Sua formação:

○ médico

○ enfermeiro

○ farmacêutico

○ Outro:

Tempo que trabalha no hospital:

\section{Sobre o hospital}

O hospital possui quantos leitos?

Quantos desses são de UTI?

Qual o tipo de financiamento?

○ público

○ privado

○ filantrópico

Qual o tipo de corpo clínico

- aberto (permite que outros médicos internem e assistam pacientes)

○ fechado (possui corpo clínico permanente)

\section{Sobre o serviço de controle de infecção}

Quantos médicos atuam no serviço de controle de infecção?

Quantos enfermeiros atuam no serviço de controle de infecção?

Quantos farmacêuticos atuam no serviço de controle de infecção?

Quantos secretários atuam no serviço de controle de infecção?

Há estagiários?

Há residentes?

Alguma outra categoria de profissional? Quantos

\section{$O$ controle de antimicrobianos}

Existe um programa de uso racional de antimicrobianos?

○ Sim

○ Não. Se esta fora opção, pule a próxima seção

Há um profissional responsável pelo programa?

$\begin{array}{ll}\circ & \text { Sim } \\ \circ & \text { Não }\end{array}$

Qual a sua formação?

○ médico

○ enfermeiro

- farmacêutico

○ Outro: 
Que profissionais atuam no programa?

○ médicos

○ enfermeiros

- farmacêuticos

○ biomédicos

○ biólogos

Quantas horas por dia por profissional são dedicadas ao controle de antimicrobianos?

\section{Ferramentas e estratégias}

Existe algum membro do programa que realize as visitas nas unidades de internação?

○ Sim

○ Não

Qual a periodicidade?

Há uma via para consultar o especialista do programa remotamente?

○ Sim

○ Não

Qual o modo de consultá-lo?

por telefone, aplicativo de celular, pedido de interconsulta, pelo sistema informatizado, etc Existe prescrição eletrônica?

- Sim

○ Não

em parte das unidades de internação

Existe algum mecanismo de avaliação sistemática de antimicrobianos prescritos?

○ Sim

○ Não

O que é avaliado?

o dose

O indicação

○ tempo de tratamento

Há necessidade de autorização prévia a administração de antibióticos (pré-autorização)?

- Sim, para todos

○ Não

Para alguns antimicrobianos

Quais?

caso tenha marcado opção "para alguns antimicrobianos", favor informe-os

Após o resultado das culturas existe reavaliação da prescrição?

○ Sim

○ Não

Existe avaliação após a prescrição (auditoria pós-prescrição)?

Caso o programa não faça o controle total de antimicrobianos previamente à administração

○ Sim

○ Não

Se existe avaliação após a prescrição, há devolutiva para o prescritor?

- Sim

○ Não

Existe sistema de apoio à decisão?

- Sim

○ Não

Há documento para antibioticoprofilaxia cirúrgica? 
Guia, protocolo, diretriz, ou qualquer outro documento escrito

○ Sim

○ Não

Há documento para sepse?

Guia, protocolo, diretriz, ou qualquer outro documento escrito

○ Sim

○ Não

Há mecanismos que diminuam o uso de antibióticos de mesmo espectro (terapia redundante)?

○ Sim

○ Não

É realizado monitoramento de nível sérico de algum dos seguintes antibióticos?

○ amicacina

○ vancomicina

○ carbapenêmicos

- Outro:

Existe um documento para monitoramento e ajuste para aminoglicosídeos?

- Sim

○ Não

○ não se aplica

Existe um documento para monitoramento e ajuste de vancomicina?

o Sim

○ Não

○ não se aplica

Há documento para o ajuste de dose conforme a função renal ?

○ Sim

○ Não

Há documento para o ajuste de dose conforme a função hepática ?

○ Sim

○ Não

É feita a otimização de beta lactâmicos/carbapenêmicos pela infusão estendida?

○ Sim

○ Não

O programa faz esforços para a transição de terapia endovenosa para a oral precoce?

○ Sim

○ Não

São ministradas aulas?

O $\operatorname{sim}$

○ Não

\section{Microbiologia e laboratório}

O hospital conta com laboratório próprio?

○ Sim

○ Não

A identificação de bactérias é automatizada?

○ $\operatorname{sim}$

○ não

Qual o tempo médio para identificação das bactérias

Qual o tempo médio para o resultado do teste de sensibilidade?

É feito teste viral rápido para patógenos respiratórios (VSR, influenza, etc)?

o Sim 
○ Não

Faz detecção indireta de fungos?

- Sim. Galactomana

- Sim, Beta- D-glucana

○ Não

Outro:

Faz testes para toxinas de Clostridium difficile

○ Sim

○ Não

Utiliza marcadores bioquímicos de inflamação/ infecção?

○ Sim, PCR

○ Sim, procalcitonina

○ Não

Objetivos do programa

Qual o objetivo número 1?

Qual o objetivo número 2?

Quais os objetivos do programa?

Caso não se encaixe em nenhuma das opções acima

Para alcançá-los, qual a estratégia
$\circ$ restringir
○ educar
O ambos
○ Outro:

\section{Sobre o monitoramento do programa}

Quais os indicadores utilizados?

○ adesão aos protocolos

○ taxa de infecções por Clostridium difficile?

- perfil de resistência de bactérias

- duração de tratamento (equivalente a DOT, days of therapy)

- DDD (dose diária dispensada)

- Custos com antimicrobianos

○ incidência de infecção por multirresistentes

A quem são divulgados esses indicadores?

o diretoria

- chefes de departamento

○ corpo clínico

○ equipe multiprofissional

○ é disponibilizado a todos

- Outro:

Na sua opinião, o que já funciona no controle de antimicrobianos na prática? 


\section{REFERÊNCIAS BIBLIOGRÁFICAS}

1. Rosa M, Moreira Reis M, Lima. A farmácia e o controle das infecções hospitalares. In Gomes MJVM. Ciências farmacêuticas: uma abordagem em farmácia hospitalar. 1st ed. São Paulo : Atheneu; 2006. p. 407-427.

2. Nikaido. Multidrug Resistance in bacteria. Annu Rev Biochem. 2009;: p. 119-146.

3. Habboush, Guzman. Antibiotic Resistance Treasure Island: NCBI Bookshelf; 2018.

4. Malta D, Cezário, Moura Ld, Morais Neto O, Silva Junior. A construção da vigilância e prevenção das doenças crônicas não transmissíveis no contexto do Sistema Único de Saúde. Epidemiol. Serv. Saúde. 2006 set; 15(3).

5. Ruiz-Garbajosa , Cantón. Epidemiología de los bacilos gramnegativos. Rev Esp Quimioter. 2016; 29: p. 21-25.

6. Carvalho LR, Campos C, Franco MdC, Rocha DM, Ercole. Incidência e fatores de risco para infecção de sítio cirúrgico. Rev. Latino-Am. Enfermagem. 2017.

7. Shepard, Ward W, Milstone A. Financial Impact of Surgical Site Infections on Hospitals. JAMA. 2013; 148(10).

8. Valiquette L, Chakra CNA, Laupland KB. Financial impact of health care-associated infections: When money talks. Can J Infect Dis Med Microbiol. 2014; 25(2): p. 71-74.

9. Cilloniz, Martin-Loeches I, Garcia-Vidal, San Jose A, Torres A. Microbial etiology of pneumonia: epidemiology, diagnosis and resistnace patterns. Int. J. Mol. Sci. 2016; 17(2120).

10. Ribas RM, Gontijo Filho PP, Cezário RC, Silvia PF, Langoni DRP, Duque S. Fatores de risco para colonização por bactérias hospitalares multirresistentes em pacientes críticos, cirúrgicos e clínicos em um hospital universitário brasileiro. Revista médica de Minas Gerais. 2008 jan; 19(3).

11. World Health Organization. Global priority list of antibiotic-resistant bacteria to guide research, discovery and development of new antibiotics. ; 2017.

12. Center for Disease Dynamics, Economics \& Policy. State of the World's Antibiotics Washington : CDDEP; 2015.

13. Han Z, Petit NN, Landon EM, Brielmeier BD. Impact of Pharmacy Practice Model Expansion on Pharmacokinetic Services: Optimization of Vancomycin Dosing and Improved Patient Safety. Hosp Pharm. 2017 abr; 52(4): p. 273-279.

14. Bruin Ad, Riley LW. Does vancomycin prescribing intervention affect vancomycinresistant enterococcus infection and colonization in hospitals? A systematic review. BMC Infect Dis. 2007 Abr; 7(4).

15. Levitus M, Perera TB. Vancomycin-Resistant Enterococci (VRE) Treasure Island: StatPearls; 2018.

16. Boszczowski I. Análise espacial da ocorrência de infecções bacterianas da corrente sanguínea causadas por agentes multirresistentes em unidades de terapia intensiva do 
estado de São Paulo. Tese apresentada à FMUSP para ontenção do título de Doutor em ciências. 2017.

17. Zou YM, Ma Y, Liu JH, Shi J, Fan T, Shan YY, et al. Trends and correlation of antibacterial usage and bacterial resistance: time series analysis for antibacterial stewardship in a Chinese teaching hospital (2009-2013). Eur J Clin Microbiol Infect Dis. 2015; 34: p. 795-803.

18. Santos SRCJ, Lanchote VL, Giraud. Controle terapêutico. In Oga S, Camargo , Batistuzzo JAO. Fundamentos de toxicologia. 4th ed. São Paulo: Atheneu ; 2014. p. 97109.

19. Klingenberg, Kornelisse RF, Buonocore, Maier RF, Stocker M. Culture-Negative Early-Onset Neonatal Sepsis - At the Crossroad Between Efficient Sepsis Care and Antimicrobial Stewardship. Front. Pediatr. 2018 out.

20. Yoneyama H, Katsumata R. Antibiotic Resistance in Bacteria and Its Future for Novel Antibiotic Development. Bioscience, Biotechnology, and Biochemistry. 2006; 70(5): p. 1060-1075.

21. MacDougall C, Polk E. Antimicrobial Stewardship Programs in Health Care Systems. Clinical microbiology reviews. 2005 out; 18(4): p. 638-656.

22. Srinivasan A. Antibiotic stewardship: why we must, how we can. Cleve Clin J Med. 2017 set; 84(9).

23. McGowan JE, Gerding DN. Does antibiotic restriction prevent resistance? New Horiz. 1996 ago; 4: p. 370-6.

24. Dyar OJ, Buttner B, Schouten J, Pulcini C. What is antimicrobial stewardship? Clin Microbiol Infect. 2017 nov; 23(11): p. 793-798.

25. Truong R, Yamaki J. The hospital antimicrobial use process: from beginning to end. Perpectives OFID. 2018 março 13;: p. 1-5.

26. Oselka. Prescrição de antibióticos e as comissões de controle de infecção hospitalar. Rev. Assoc. Med. Bras. 2001 jun; 47(2).

27. Karanika S, Paudel S, Grigoras, Kalbasi E, Mylonakis E. Systematic Review and Metaanalysis of Clinical and Economic Outcomes from the Implementation of HospitalBased Antimicrobial Stewardship Programs. Antimicrobial agents and Chemotherapy. 2016 agosto; 60(8): p. 4840 - 4852.

28. Infectious Disease Society of America. Implementing an Antibiotic Stewardship Program: Guidelines by the Infectious Diseases Society of America and the Society for Healthcare Epidemiology of America. Clinical Infectious Disease. 2016 maio 15; 62(10): p. 51-77.

29. Valiquette, Cossette B, Garant MP, Diab H, Pepin J. Impact of reduction in the use of high-risk antibiotics on the course of an epidemic of Clostridium difficile-associated disease caused by Hypervirulent NAP/027 Strain. CLinical Infectious Disease. 2007; 1(45): p. 112-121.

30. Center for Disease control and Prevention. Core Elements of Hospital Antibiotic Stewardship Programs. 2017 fevereiro 23. 
31. Mehta MD, Haynes K, Wileyto P, Gerber JS, Timko DR, Morgan SC, et al. Comparison of Prior Authorization and Prospective Audit with feedback fos Antimicrobial stewardship. Infect control hosp epidemiol. 2014 set; 35(9): p. 1092-1099.

32. Pakyz L, Moczygemba LR, VanderWielen LM, Edmond MB, Stevens MP. Facilitators and barriers to implementing antimicrobial stewardship. Am J Infect Control. 2014 out; 4210: p. 257-63.

33. Nathwani D, Lawson W, Dryden M, Stephens J, Corman S, Solem C, et al. Implementing criteria-based early switch/early discharge programmes: a European perspective. Clin Microbiol Infect. 2015 Jul.

34. Pereira NR, Castro-Sanchez E, Nathwani D. How can Multi-Professional Education Support Better Stewardship? Infect Dis Rep. 2017 mar; 9(1).

35. Veiga P, Paiva J. Pharmacokinetics-pharmacodynamics issues relevant for the clinical use of beta-lactam antibiotics in critically ill patients. Critical Care. 2018 set.

36. Bartal C, Danon A, Shlaeffer F, Reisemberg K, Alkan, Smoliakov R, et al. Pharmacokinetic dosing of aminoglycosides: a controlled trial. The American Journal of Medicine. 2003 fev; 114(3): p. 194-198.

37. Hospital Israelita Albert Einstein. Protocolo de vancocinemia. 2012.

38. Almeida SH. Incorporação de novas tecnologias de informação em um sistema de distribuição de medicamentos: avaliação quanto ao aumento de segurança do paciente.. 2010 .

39. Tavares. Proposta de sistema de apoio à decisão para controle de gerenciamento agrícola em usinas de açucar e álcool. 2008.

40. Vasconcelos B, Henriques, Rocha. Modelo para o desenvolvimento de Sistemas de Apoio à Decisão Clínica. Universidade Fernando Pessoa. .

41. Simões S, Maia MR, Gregório J, Couto I, Asfeldt AM, Simmonsen GS, et al. Participatory-Implementation of an antibiotic stewardship programme supported by an innovative surveillance and clinical decision-support system. J Hosp Infect. 2018 Jul.

42. Nachtigall I, Tafelski S, Halle E, DEja M, Grebe MC, Tamarkin A, et al. Long-term effect of computer-assisted decision support for antibiotic treatment in critically ill patients: a prospective ‘before/after' cohort study. BMJ Open. 2014.

43. Monika L, Vogt-Ferrier NB. Antibiotic duration for treating uncomplicated, symptomatic lower urinary tract infections in elderly women. Cochrane Database of Systematic Reviews. 2002.

44. Elwood NR, Guidry A, Duane TM, Cushiere J, Cook CH, O`Neil PJ, et al. Short-Course Antimicrobial Therapy Does Not Increase Treatment Failure Rate in Patients with IntraAbdominal Infection Involving Fungal Organisms. Surgical infections. 2018 Mai; 19(4).

45. Pulcini , Gyssens IG. How to educate prescribers in antimicrobial stewardship practices. Virulence. 2013; 4(2): p. 192-202.

46. Silva Junior M. Recentes mudanças da infecção por. Einstein. 2012; 10(1): p. 105-109.

47. Bartlett JG. Clostridium difficille infection. Infectious Disease Clinics of North 
America. 2017 setembro ; 31(3): p. 489-495.

48. Pasternak. Novas metodologias de identificação de micro-organismos: MALDI-TOF. Einstein. 2012; 10(q).

49. Araujo MRE. Hemocultura: recomendações de coleta, processamento e interpretação dos resultados. J Infect Control. 2012; 1(1): p. 8-19.

50. Lee A, Mirrett S, Reller L, Weinstein MP. Detection of bloodstream infections in adults: how many blood cultures are needed? J Clin Microbiol. 2007 vov; 45(11): p. 3546-8.

51. Beekmann SE, Diekema DJ, Chapin KC, Doern GV. Effects of Rapid Detection of Bloodstream Infections on Length of Hospitalization and Hospital Charges. J. Clin, Microbiol. 2003; 41(7): p. 3119-3125.

52. Cockerill FR, Reed GS, Hughes JG, Torgerson CA, Vetter EA, Harmsen WS, et al. Clinical comparison of BACTEC 9240 plus aerobic/F resin bottles and the isolator aerobic culture system for detection of bloodstream infections. J Clin Microbiol. 1997 Jun; 35(6): p. 1469-72.

53. Woźniak-Kosek A, Kempińska-Mirosławska B, Hoser G. Detection of the influenza virus yesterday and now. Acta Biochim Pol. 2014 set; 61(3): p. 465-70.

54. Nyquist AC, Gonzales R, Steiner J. Antibiotic Prescribing for Children With Colds, Upper Respiratory Tract Infections, and Bronchitis. JAMA. 1998; 279(11): p. 875-877.

55. Berquó LS, Barros AJD, Lima RC, Bertoldi AD. Utilização de medicamentos para tratamento de infecções respiratórias na comunidade. Universidade Federal de Pelotas. 2000; [dissertação de mestrado].

56. Cantais A, Mory O, Pillet, Verhoeven PO, Bonneau J, Patural H, et al. Epidemiology and microbiological investigations of community-acquired pneumonia in children admitted at the emergency department of a university hospital. J Clin Virol. 2014 ago; 60(4): p. 402-7.

57. Havers F, Thaker, Clippard JR, Jackson M, McLean HQ, Gaglani, et al. Use of influenza antiviral agents by ambulatory care clinicians during the 2012-2013 influenza season. Clin Infect Dis An Off Publ Infect Dis Soc Am. 2014; 59: p. 774-782.

58. Valones MA, Guimarães RL, Brandão LC, Souza PE, Carvalho T, Crovela S. Principles and applications of polymerase chain reaction in medical diagnostic fields: a review. Braz J Microbiol. 2009 jan; 40(1).

59. Granato C, Sampaio L, Lázari S. Fleury. [Online].; 2012 [cited 2019 jan 30. Available from: http://www.fleury.com.br/medicos/educacao-medica/artigos/Pages/testemolecular-permite-pesquisar-17-virus-respiratorios.aspx.

60. Carolina O. Proteína $\mathrm{C}$ reativa versus procalcitonina para orientar a duração da terapia antimicrobiana em pacientes sépticos internados em centro de terapia intensiva. Universidade Federal de Minas Gerais. 2012; [tese de doutorado].

61. Patterson TF, Donnelly JP. New Concepts in Diagnostics for Invasive Mycoses: NonCulture-Based Methodologies. J Fungi. 2019; 5(9).

62. Ruhnke M. Antifungal stewardship in invasive Candida infections. Clin Microbiol 
Infect. 2014 jun; 20(6).

63. Bishop J, Kong DC, Schulz TR, Thursky KA, Buising L. Meeting the challenge for effective antimicrobial stewardship programs in regional, rural and remote hospitals what can we learn from the published literature? Rural and Remote Health. 2018 maio $24 ; 18(2)$.

64. Haque A, Hussain K, Ibrahim R, Abbas Q, Ahmed SA, Jumair H, et al. Impact of pharmacist-led antibiotic stewardship program in a PICU of low/middle-income country. BMJ Open Quality. 2018; 7.

65. Emberger J, Tassone D, Stevens P, Markley JD. The Current State of Antimicrobial Stewardship: Challenges, Successes, and Future Directions. Current Infectious Disease Reports. 2018; 20(31).

66. Bertollo LG, Lutkemeyer DS, Levin AS. Are antimicrobial stewardship programs effective strategies for preventing antibiotic resistance? A systematic review. Am J Infect control. $2018 \mathrm{Jul}$; 46(7): p. 824-836.

67. Schuts C, Hulscher ME, Mouton W, Verduin CM, Cohgen Stuart W, Overdiek W, et al. Current evidence on hospital antimicrobial stewardship objectives: a systematic review and meta-analysis. The Lancet Infectious disease. 2016 Julho ; 16(7): p. 847-856.

68. Zaoutis TE, Prasad PA, Localio AR, Coffin SE, Bell LM, Walsh TJ, et al. Risk Factors and Predictors for Candidemia in Pediatric Intensive Care Unit Patients: Implications for Prevention. Clin Infect Dis. 2010 set; 51(5).

69. Vollaard EJ, Classener HA. Colonization resistance. Antimicrob Agents Chemother. 1994; 38(3): p. 409-414.

70. Moehning W, Anderson J, Cochran L, Hicks LA, Srinivasan A, Dodds Ashley S. Expert Consensus on Metrics to Assess the Impact of Patient-Level Antimicrobial Stewardship Interventions in Acute-Care Settings. Healthcare epidemioloy. 2017; 64(3): p. 377-383.

71. Bassetti , Di Biagio A, Rebesco , Amalfitano, Topal J, Bassetti D. The effect of formulary restriction in the use of antibiotics in an Italian hospital. Eur $\mathbf{J}$ Clin Pharmacol. 2001 set; 57: p. 529-534.

72. Huang H, Kim B. Impact of an infectious diseases specialist-led antimicrobial stewardship programmes on antibiotic use and antimicrobial resistance in a large Korean hospital. Sci Rep. 2018 out; 8(1).

73. Assis DB. Avaliação do impacto de medidas de intervenção em unidade de terapia intensiva do estado de São Paulo. tese apresentada à Faculdade de Medicina da Universidade de São Paulo. 2018 nov.

74. Correa. Restrição do uso de antimicrobianos no ambiente hospitalar. Educ Contin Saúde. 2007;: p. 48-52.

75. Brasil. Portaria 2616 de 12 de maio de 1998. Ministério da Saúde. 1998 mai; dispõe sobre a obrigatoriedade da manutenção pelos hospitais do país, de Programa de Controle de Infecções Hospitalares.

76. Dantas SCC. Farmacia e Controle das infecções hospitalares. Pharmacia brasileira. 2011 fev; 50 . 
77. Hepler CD, Strand LM. Opportunities and responsibilities in pharmaceutical care. Am J Hosp Pharm. mar 1990; 473: p. 533-43.

78. Silva U. A importância do controle da prescrição de antimicrobianos em hospitais para melhoria da qualidade, redução dos custos e controle da resistência bacteriana. Prática hospitalar. 2008.

79. Chahine EB, El-Lababidi RM, Sourial M. Engaging Pharmacy Students, Residents, and Fellows in Antimicrobial Stewardship. J Pharm Pract. 2015 dez; 28(6): p. 585-91.

80. Brasil. Ministério da Saúde. I Fórum Nacional de Educação farmacêutica. Ministério da Saúde. 2008.

81. da Silva GAR. O processo de tomada de decisão na prática clínica: a medicina como estado da arte. Rev Bras Clin Med. São Paulo. 2013 jan-mar; 111: p. 75-9.

82. CDC. Centers for Disease Control and Prevention Guideline for the Prevention of Surgical Site Infection. JAMA. 2017 ago;: p. 784-791.

83. Classen DC, Evans, Pestotnik SL, Horn SD, Menlove RL, Burke JP. The Timing of Prophylactic Administration of Antibiotics and the Risk of Surgical-Wound Infection. N Engl J Med. 1992 jul; 326: p. 281-286.

84. Dellinger RP, Levy MM, Rhodes A, Annane D. Surviving Sepsis Campaign: International Guidelines for Management of Severe Sepsis and Septic Shock, 2012. Intensive Care Med. 2013 fev; 39(165).

85. Leung V, Wu JHC, Langford BJ, Garber G. Landscape of antimicrobial stewardship programs in Ontario: a survey of hospitals. CMAJ OPEN. 2018; 6(1).

86. Abramovicius. Estudo dos erros de prescrição relacionados aos medicamentos utilizados no Hospital das Clínicas da Faculdade de Medicina de Ribeirão Preto. Faculdade de medicina de Ribeirão Preto da Unoversidade de São Paulo. 2007; [dissertação].

87. Sousa FREGdEGd. A segurança de pacientes na terapêutica medicamentosa: análise da redação da prescrição médica nos erros de administração de medicamentos em unidades da clínica médica. Dissertação de mestrado. 2007.

88. Gallagher JC, Justo JA, Chahine EB, Bookstaver PB, Scheetz, Suda J, et al. Preventing the Post-Antibiotic Era by Training Future Pharmacists as Antimicrobial Stewards. American Journal of Pharmaceutical Education. 2018; 80(6): p. 627-634.

89. Camargo LFA. Uso de antimicrobianos: restringir ou não? einstein: Educ Contin Saúde. 2007; 5(2): p. 48-52.

90. Collins D, Miller DE, Kenney M, Mynatt RP, Tiberg D, Cole K, et al. The steate of antimicrobial stewardship in Michigan: results of a stetewide survey on antimicrobial stewardship efforts in acute care hospitals. Hosp Pharm. 2015 mar; 50(3): p. 180-184.

91. Mc Gowan , Finland M. Usage of Antibiotics in a General Hospital: Effect of Requiring Justification. The Journal of Infectious Diseases. 1974 ago; 130 (2).

92. White AC, Atmar RL, Wilson J, Cate TR, Stager E, Greenberg B. Effects of Requiring Prior Authorization for Selected Antimicrobials: Expenditures, Susceptibilities, and Clinical Outcomes. CID. 1997 mar; 25: p. 230-239. 
93. Tamma PD, Putcha N, Suh YD, Van Arendonk KJ, Rinke L. Does prolonged $\beta$-lactam infusions improve clinical outcomes compared to intermittent infusions? A metaanalysis and systematic review of randomized, controlled trials. BMC Infectious Diseases. 2011 abr; 11181.

94. Bhowmick, Kim TJ, Hetherington F, Takavarasha S, Sandhu SS, Gandhi S, et al. Collaboration between an antimicrobial stewardship team and the microbiology laboratory can shorten time to directed antibiotic therapy for methicillin-susceptible staphylococcal bacteremia and to discontinuation of antibiotics for coagulase-negative stap. Diagn Microbiol Infect Dis. 2018 nov; 92(3): p. 214-219.

95. Kothar , Morgan , Haak. Emerging Technologies for Rapid Identification of Bloodstream Pathogens. CID. 2014 jul;: p. 272-278.

96. Nunes K, Lacerda RA, Jardim JM. Revisão sistemática e metanálise sobreo valor preditivo da proteína C-reativa em infecção pós-operatória. ev Esc Enferm USP. 2011; 45(6).

97. Oliveira C, Botoni F, Oliveira CR, Silva C, Pereira, Serufo J, et al. Procalcitonin Versus C-Reactive Protein for Guiding Antibiotic Therapy in Sepsis: A Randomized Trial. Critical Care Medicine. 2013 out; 41(10).

98. Wirz Y, Meier MA, Bouadma L, Luyt E, Wolff M, Chastre J, et al. Effect of procalcitonin-guided antibiotic treatment on clinicla outcomes in intensive care unit patients with infection and sepsis patients: a patient-level meta-analysis of randomized trials. Critical Care. 2018 ago; 22(1).

99. Moura EC, Lima AM, Urdaneta M. Uso de indicadores para o monitoramento das ações de promoção e atenção da Política Nacional de Atenção Integral à Saúde do Homem (PNAISH). Ciência e saúde coletiva. 2012; 17(10): p. 2597-2606.

100. Paudel S, Karanika S, Grigoras C, Kalbasi A, Eleftherios Mylonakis E. Clinical and Economic Outcomes from the Implementation of Hospital-based Antimicrobial Stewardship Programs: A Systematic Review and Meta-Analysis. Antimicrob. Agents Chemother. 2016 mai.

101. Mota DM, Silva GC, Sudo EC, Ortun V. Uso racional de medicamentos: uma abordagem econômica para tomada de decisões. Ciênc. saúde coletiva. 2008; 13.

102. Fernandes Q, Souza , Brito MA, Tavares N, Matos V, Souza MdOB. Impacto farmacoeconômico da racionalização do uso de antimicrobianos em unidades de terapia intensiva. Rev Bras Farm Hosp Serv Saúde. 2012 dez; 3(2): p. 10-14.

103. Rosa G, Goldani Z, Santos R. Association between adherence to an antimicrobial stewardship program and mortality among hospitalised cancer patients with febrile neutropaenia: a prospective cohort study. BMC Infectious Disease. 2014; 14(286).

104. Koselleck R. Futuro passado Rio de Janeiro: PUC-Rio; 2012. 


\section{APÊNDICE}

\section{Produto final: Proposta para curso de aperfeiçoamento em controle de infecção e farmacoterapia de doenças infecciosas}

Unidade administrativa: Instituto da Criança

Público-alvo: farmacêuticos

\section{Apresentação}

O "Primeiro fórum de educação farmacêutica: o farmacêutico que o Brasil necessita" trouxe em sua primeira edição as falhas no ensino farmacêutico (1):

"a educação farmacêutica ainda é desenvolvida de forma
desarticulada da realidade social, pouco comprometida com a
resolução dos problemas nacionais de saúde."

Um das necessidades apontadas é a formação de um profissional capaz de intervir na realidade em que esteja inserido, tendo como base a ciência, a ética e a visão crítica e interdisciplinar (1).

$\mathrm{Na}$ atual conjuntura de mudanças do acesso à informação, das dinâmicas de atuação dos profissionais, surgem questionamentos sobre a metodologia do próprio sistema de ensinoaprendizagem. A aprendizagem baseada em problemas vem tentar solucionar algumas das demandas do ensino (2).

Essa nova forma de ensino teve origem no Canadá na década de 1960 e valoriza a autonomia do aluno em buscar informações de forma ativa, integra conhecimentos, ensina o trabalho em equipe formando um profissional cooperativo, respeitoso (2).

O método consiste em fornecer um problema ao grupo de discentes que percorrem alguns passos antes de solucioná-lo. Ler o enunciado, identificar o problema, formular 
hipóteses, busca das soluções individualmente, compartilhamento de informações adquiridas, discussão da resolução dos problemas em grupo (2).

A pesquisa intitulada "Avaliação dos programas de uso racional de antimicrobianos em hospitais do estado de São Paulo" foi desenvolvida na Faculdade de Medicina da Universidade de São Paulo com o objetivo de detectar lacunas no que diz respeito ao funcionamento das unidades de controle de antimicrobianos.

Verificou-se que há poucos farmacêuticos atuando no serviço de controle de infecção ou na cadeia de uso de antimicrobianos, apesar dos conhecimentos deste profissional agregarem valor às intervenções em serviços de saúde.

Uma dessas propostas é a estruturação de formas de educação continuada para farmacêuticos por eixos que contemplem aquisição de conhecimento e aprendizagem por método ativo.

Divisão: divisão técnica multiprofissional / serviço de farmácia

Público-alvo: farmacêuticos.

\section{Justificativa}

Há necessidade de preparar o farmacêutico a ser ator na promoção do uso responsável de antimicrobianos complementando e integrando seus conhecimentos em microbiologia, imunologia, biologia molecular, farmacocinética, farmacodinâmica, toxicologia, epidemiologia e administração em saúde. 


\section{Demandas de mercado}

No estado de São Paulo, estão em atividade 171 cursos superiores de farmácia e / ou farmácia e bioquímica reconhecidos pelo MEC dos quais apenas seis são oferecidos por instituições públicas, são oferecidos também 59 cursos de especialização em farmácia clínica.

O CFF reconhece as seguintes linhas de atuação do farmacêutico especialista:

i - alimentos;

ii - análises clínico-laboratoriais;

iii - educação;

iv - farmácia;

v - farmácia hospitalar e clínica;

vi - farmácia industrial;

vii - gestão;

viii - práticas integrativas e complementares;

ix - saúde pública;

$\mathrm{x}$ - toxicologia.

A farmácia clínica, especialidade que aparece juntamente com a farmácia hospitalar, evolui continuamente desde os anos 1960 quando a Food and Drug Administration (FDA) junto à American Medical Association (AMA) nos Estados Unidos da América iniciaram o debate em torno das reações adversas a medicamentos. No Brasil, em 1995, foi criada a Sociedade Brasileira de Farmácia Hospitalar (SBRAFH) que concedem o título de especialista em farmácia hospitalar e em farmácia clínica mediante comprovação de proficiência nessas áreas (3). Não existe o reconhecimento de farmacêuticos atuantes em terapia intensiva, pediatria, doenças infecciosas, etc.

Além disso, há aproximadamente 70 possibilidade de carreira que os farmacêuticos podem seguir. Dessa forma, é muito difícil que o estudante saia do ensino superior com todo o conhecimento de todas as áreas. 


\section{Demandas sociais}

No Brasil, os gastos com a saúde estão em torno de $8 \%$ do PIB, porém o sistema ainda não é o ideal. Uma das dificuldades é a formação de profissionais em cursos que garantam que o egresso tenha capacidade de integrar o aprendizado técnico-científico às reais demandas da sociedade.

"Profissionais com formação sem qualidade fazem mal à saúde dos brasileiros. [...] É interessante observar que mesmo com o grande contingente de formados, o problema de desigualdade na distribuição dos profissionais pelo país persiste” (4)

O preparo de profissionais que saibam analisar custo-benefício e elaborar estudos farmacoeconômicos é necessário para que não haja dispêndios.

\section{Objetivos do curso}

Propiciar bases para a atuação em serviços de controle de infecção, com ênfase na prescrição segura de antimicrobianos.

\section{Objetivos específicos:}

O egresso deverá estar preparado para atuar em grupo de combate às infecções hospitalares desde o monitoramento do tratamento com antimicrobianos até tomada de decisão.

Ao final do curso, espera-se que o farmacêutico que atue em farmácia comunitária esteja apto a ser o elo entre a prescrição e a adesão ao tratamento, orientando paciente e quando necessário questionando o prescritor. Ao farmacêutico hospitalar ou clínico, que esteja preparado auxiliar no uso racional de antimicrobianos.

Além disso, é desejado que o egresso desenvolva habilidades como a cooperação, o desenvolvimento de autonomia e a prática da reflexão. 


\section{Metodologia}

Aprendizagem baseada em problemas (metodologia ativa), aulas expositivas, estudos de casos, pesquisas bibliográficas, trabalho em grupo e seminários.

As primeiras disciplinas, as básicas, serão cumpridas por exposição das aulas.

Os temas serão agrupados em módulos. Os módulos estão descritos logo abaixo

\section{Carga horária}

80 horas

\section{Avaliação do discente}

O Certificado de Conclusão será conferido aos alunos que tiverem concluído no mínimo 75\% (setenta e cinco por cento) da carga horária do Curso e que obtiverem média final mínima de 7,0 (sete), quando houver avaliação. Caberá ao Coordenador do Curso estabelecer se o aluno terá direito a recuperação, definindo quantas tentativas de avaliação poderão ser realizadas.

O certificado digital será emitido pela Escola de Educação Permanente do Hospital das Clínicas da Faculdade de Medicina da Universidade de São Paulo - EEP/HCFMUSP.

\section{Componenente curricular}

- Doenças de origem bacteriana;

- Doenças causadas por fungos;

- Doenças causadas por vírus,

- Análise de prescrições; 
Plano de ensino

Eixo 1 - Componentes básicos em aulas expositivas.

Componente curricular: Doenças de origem bacteriana

\begin{tabular}{|l|l}
\hline Aulas semanais: 5 & Total de horas: 20 \\
\hline
\end{tabular}

Ementa: a disciplina recapitula o estudo da célula bacteriana, o metabolismo das diferentes bactérias, componente celular, procedimentos diagnósticos atuais, além de oferecer ao estudante tratamento por diferentes classes de quimioterápicos antimicrobianos, mecanismos de resistência e do uso de antimicrobianos.

Objetivos:

Conhecer os principais agentes patogênicos de comunidade e de ambiente hospitalar

Conhecer os tratamentos mais utilizados

Conteúdo programático

- Doenças causadas por bactérias Gram-positivas e tratamento: Staphylococcus spp., Streptococcus, Enterococcus spp.;

- Doenças causadas por bacilos gram-negativos: Enterobacteriaceae e Bacilos não fermentadores;

- Betalactâmicos clássicos - penicilinas e cefalosporinas;

- Betalactâmicos não-clássicos - carbapenêmicos, monobactam e inibidores de betalactamases;

- Macrolídeos;

- Lincosamídicos;

- Polipeptídeos - polimixinas, glicopeptídeos, bacitracina;

- Aminoglicosídeos;

- Tetraciclinas;

- Anfenicóis;

- Quinolonas;

- Sulfamídicos;

- Tuberculostáticos e medicamentos para hanseníase.

Bibliografia complementar sugerida

Santos L, Santos O, Freitas Cd, Ferreira A, Afonso IF, Rodrigues R, et al. Staphylococcus 
aureus: visitando uma cepa de importância hospitalar. J. Bras. Patol. Med. Lab. 2007; 43 (5) Appelbaum PC. Antimicrobial Resistance in Streptococcus pneumoniae: An Overview. Clinical Infectious Diseases. 1992; 15 (6)

Barroso DE, Carvalho Md, Nogueira SA, Solari CA. Doença meningocócica: epidemiologia e controle dos casos secundários. Rev. Saúde Pública. 1998; 32 (7)

DeLucia R, Oliveira-Filho RM, Planeta CS, Gallacci M, Avellar MCW. Farmacologia integrada. 3rd ed. Rio de Janeiro: Revinter; 2007. (8)

Componente curricular: Doenças causadas por fungos

\begin{tabular}{|l|l}
\hline Aulas semanais: 5 & Total de horas: 10 \\
\hline
\end{tabular}

Ementa: a disciplina fornece bases para o raciocínio clínico tratamento

Objetivos:

Conhecer as diferentes classes de antifúngicos;

Conhecer os espectros de antifúngicos bem como as características farmacocinéticas.

Conteúdo programático

- Anfotericina B

- Equinocandinas

- Triazólicos

- Imidazólicos

Bibliografia sugerida

Hamill RJ. Amphotericin B formulations: a comparative review of efficacy and toxicity. Drugs.. 2013; 73(9). (9)

\section{Componente curricular: Doenças causadas por vírus}

\begin{tabular}{l|l} 
Aulas semanais: 5 & Total de horas: 10
\end{tabular}

Ementa: a disciplina propõe o estudo dos vírus o estudo das doenças causadas por vírus e o tratamento

Objetivos:

Fornecer conhecimento atualizado no combate às principais doenças virais

Conteúdo programático 
- Quimioterapia antiviral para tratamento da AIDS: inibidores nucleosídeos da transcriptase reversa, inibidores não nuceosídeos da transcriptase reversa, inibidores de protease, inibidores de fusão, inibidores de integrasse - seus principais eventos adversos e adesão ao tratamento;

Indicações e eventos adversos de:

- Aciclovir, ganciclovir;

- Foscarnet;

- Cidofovir;

- Anti-influenza: oseltamivir ;

- Anti-hepatite: adefovir, lamivudina, tenofovir, entecavir;

- Interferons indicados para tratamento de hepatites B e C;

- Ribavirina;

- Dermatológicos: imiquimod.

Bibliografia sugerida

BRASIL. Ministério da Saúde. Protocolo clínico e diretrizes terapêuticas para manejo da infecção pelo HIV em adultos. Brasília: Ministério da Saúde; 2018.

Protocolos clínicos e diretrizes terapêuticas dos componente especializado de assistência farmacêutica 


\section{Eixo 2 - Aprendizagem baseada em problemas}

\section{Componente curricular: Análise de prescrições}

\begin{tabular}{|l|l|}
\hline Aulas semanais: 5 & Total de horas: 30 \\
\hline Ementa: a disciplina propõe a execução de todas as etapas do acompanhamento
\end{tabular}
farmacoterapêutico de diferentes perfis de paciente.

Objetivos:

Dispensar atenção farmacêutica integralmente a diferentes perfis de paciente;

Utilizar estudos farmacoeconômicos, de epidemiologia e análises baseadas em evidência para embasar decisões;

Preparar o aluno para discussões em comissões de farmácia e terapêutica e padronização de medicamentos.

Conteúdo programático

- Análise de prescrição;

- Planejamento de metas para o paciente;

- Acompanhamento farmacoterapêutico, englobando análise de prescrição, interação medicamentosa, interação fármaco-nutriente, incompatibilidade de soluções intravenosas;

- Orientação de alta;

- Análise de reações adversas a medicamentos;

- Farmacovigilância;

- Comparação entre custos de tratamento;

- Estudos de intervenções em saúde.

Bibliografia sugerida

Bases de dados

Bulas de medicamentos

Boletins de farmacovigilância 


\section{Apresentação de caso clínico}

O grupo de alunos deverá preparar um caso clínico

5 horas

\section{Apresentação de artigos}

O grupo de alunos deverá apresentar a resolução de um problema baseado em artigos científicos

5 horas

\section{Cronograma}

\begin{tabular}{|l|c|c|c|c|}
\hline & $\begin{array}{c}\text { Doenças de } \\
\text { origem } \\
\text { bacteriana }\end{array}$ & $\begin{array}{c}\text { Doenças } \\
\text { causadas por } \\
\text { fungos/ Doenças } \\
\text { causadas por } \\
\text { vírus }\end{array}$ & $\begin{array}{c}\text { Análise de } \\
\text { prescrições }\end{array}$ & $\begin{array}{c}\text { Análise de } \\
\text { prescrições/ } \\
\text { apresentação } \\
\text { dos trabalhos }\end{array}$ \\
\hline Agosto/2019 & $\mathrm{x}$ & $\mathrm{x}$ & & \\
\hline Setembro/2019 & & & $\mathrm{x}$ & \\
\hline Outubro/2019 & & & & $\mathrm{x}$ \\
\hline Novembro/2019 & & & & \\
\hline
\end{tabular}




\section{Bibliografia}

1. Leite SN, Nascimento Jr. JM, Costa , Barbano DAB. I Fórum Nacional de Educação Farmacêutica: o farmacêutico que o Brasil necessita. Interface (Botucatu). 2007; 12(25).

2. Gomes P, Rego S. Transformação da Educação Médica: É Possível formar um novo médico a partir de mudanças no método ensino-aprendizagem? Rev. bras. educ. med. 2011; 35(4): p. 557-566.

3. Storpirtis S, Ribeiro E, Marcolongo R. Novas diretrizes para assistência farmacêutica hospitalar: atenção farmacêutica/ farmácia clínica. In Gomes MJdM, Reis AMM. Ciências farmacêuticcas. São Paulo: Atheneu ; 2006. p. 521- 533.

4. Saldiva PH, Veras M. Gastos públicos com saúde: breve histórico, situação atual e perspectivas futuras. Estudos Avançados. 2018; 32(92).

5. Santos L, Santos O, Freitas Cd, Ferreira A, Afonso IF, Rodrigues R, et al. Staphylococcus aureus: visitando uma cepa de importância hospitalar. J. Bras. Patol. Med. Lab. 2007; 43(6).

6. Appelbaum PC. Antimicrobial Resistance in Streptococcus pneumoniae: An Overview. Clinical Infectious Diseases. 1992; 15(1).

7. Barroso DE, Carvalho Md, Nogueira SA, Solari CA. Doença meningocócica: epidemiologia e controle dos casos secundários. Rev. Saúde Pública. 1998; 32(1).

8. DeLucia R, Oliveira-Filho RM, Planeta CS, Gallacci M, Avellar MCW. Farmacologia integrada. 3rd ed. Rio de Janeiro: Revinter; 2007.

9. Hamill RJ. Amphotericin B formulations: a comparative review of efficacy and toxicity. Drugs.. 2013; 73(9). 